\title{
Unbiased, High-Throughput Electron Microscopy Analysis of Experience-Dependent Synaptic Changes in the Neocortex
}

\author{
DSantosh Chandrasekaran, ${ }^{1}$ Saket Navlakha, ${ }^{3}$ Nicholas J. Audette, ${ }^{1}$ DDylan D. McCreary, ${ }^{1}$ Joe Suhan, ${ }^{1}$ Ziv Bar-Joseph, ${ }^{2}$ \\ and Alison L. Barth ${ }^{1}$ \\ ${ }^{1}$ Department of Biological Sciences and Center for the Neural Basis of Cognition and 2 Machine Learning Department and Lane Center for Computational \\ Biology, Carnegie Mellon University, Pittsburgh, Pennsylvania 15213, and ${ }^{3}$ Integrative Biology Laboratory, The Salk Institute for Biological Studies, La Jolla, \\ California 92037
}

\begin{abstract}
Neocortical circuits can be altered by sensory and motor experience, with experimental evidence supporting both anatomical and electrophysiological changes in synaptic properties. Previous studies have focused on changes in specific neurons or pathways-for example, the thalamocortical circuitry, layer 4-3 (L4-L3) synapses, or in the apical dendrites of L5 neurons - but a broad-scale analysis of experience-induced changes across the cortical column has been lacking. Without this comprehensive approach, a full understanding of how cortical circuits adapt during learning or altered sensory input will be impossible. Here we adapt an electron microscopy technique that selectively labels synapses, in combination with a machine-learning algorithm for semiautomated synapse detection, to perform an unbiased analysis of developmental and experience-dependent changes in synaptic properties across an entire cortical column in mice. Synapse density and length were compared across development and during whisker-evoked plasticity. Between postnatal days 14 and 18, synapse density significantly increases most in superficial layers, and synapse length increases in L3 and L5B. Removal of all but a single whisker row for $24 \mathrm{~h}$ led to an apparent increase in synapse density in L2 and a decrease in L6, and a significant increase in length in L3. Targeted electrophysiological analysis of changes in miniature EPSC and IPSC properties in L2 pyramidal neurons showed that mEPSC frequency nearly doubled in the whisker-spared column, a difference that was highly significant. Together, this analysis shows that data-intensive analysis of column-wide changes in synapse properties can generate specific and testable hypotheses about experience-dependent changes in cortical organization.
\end{abstract}

Key words: automated; development; electron microscopy; machine learning; synapse detection; synaptic plasticity

\section{Significance Statement}

Development and sensory experience can change synapse properties in the neocortex. Here we use a semiautomated analysis of electron microscopy images for an unbiased, column-wide analysis of synapse changes. This analysis reveals new loci for synaptic change that can be verified by targeted electrophysiological investigation. This method can be used as a platform for generating new hypotheses about synaptic changes across different brain areas and experimental conditions.

\section{Introduction}

Abundant anatomical and electrophysiological evidence indicates that synapses across the brain are shaped by in vivo experience. Typically, these experiments are directed toward examination of synapses from a specific brain area implicated

Received April 13, 2015; revised Oct. 27, 2015; accepted Nov. 9, 2015.

Author contributions: S.C., N.J.A., Z.B.-J., and A.L.B. designed research; S.C., N.J.A., D.D.M., and J.S. performed research; S.N. and J.S. contributed unpublished reagents/analytic tools; S.C., N.J.A., and D.D.M. analyzed data; S.C. and A.L.B. wrote the paper.

This work was supported by National Institute of Health Grants DA017188 (A.L.B.) and F32-MH099784 (S.N.), the McKnight Foundation (A.L.B.), the Society for Neuroscience Award for Innovation in Neuroscience (A.L.B.), National Science Foundation Grant DBI-1356505 (Z.B.J.), and the James S. McDonnell Foundation Scholars Award in Studying Complex Systems (Z.B.J.). We thank Joanne Steinmiller for expert animal care, Victor Mann, Megumi Matsushita, Joseph Sombeck, and Emma Burnett for assistance in image collection, and members of the Barth laboratory for critical comments on this manuscript. We also thank Drs. Nathan Urban, Marlene Cohen, Carl Olson, and Stanislaw Glazewski for expert opinion and critical comments on experimental design and data analysis. in sensation or behavioral output, such as in sensory cortex after altered sensory input, in the amygdala after fear conditioning, or in the hippocampus after spatial navigation and recall tasks. Typically, only a small region of the selected brain area is examined because of the experimental difficulty required to characterize these changes. For example, in the barrel field within the primary somatosensory (S1) cortex, in vivo imaging of dendritic spines, originating from apical dendrites

The authors declare no competing financial interests.

Correspondence should be addressed to Dr. Alison Barth, Department of Biological Sciences and Center for the Neural Basis of Cognition, Carnegie Mellon University, 4400 Fifth Avenue, Pittsburgh, PA 15213. E-mail: barth@cmu.edu.

S. Navlakha's present address: Center for Integrative Biology, The Salk Institute for Biological Studies, La Jolla, CA 92037. DOI:10.1523/JNEUROSCI.1573-15.2015

Copyright $\odot 2015$ the authors $\quad 0270-6474 / 15 / 3516450-13 \$ 15.00 / 0$ 
A

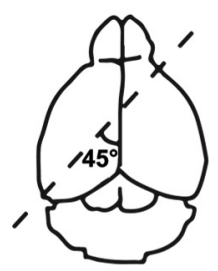

B

D

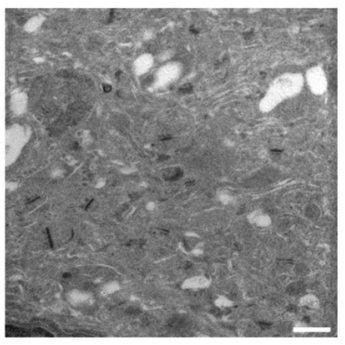

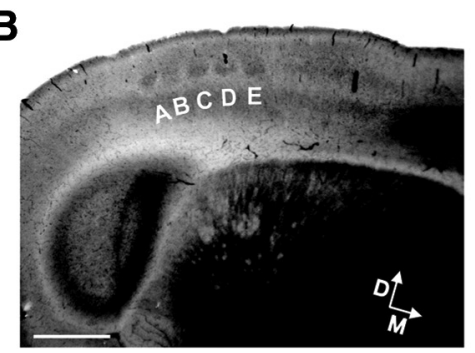

$\mathbf{E}$

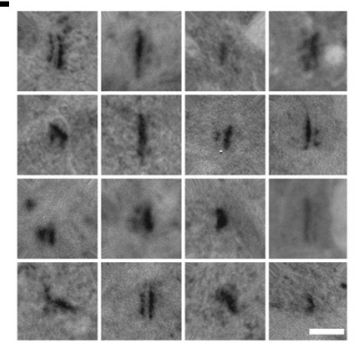

C

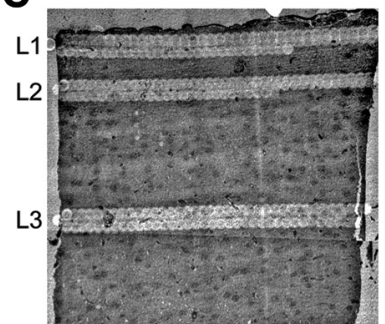

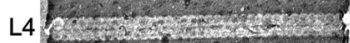

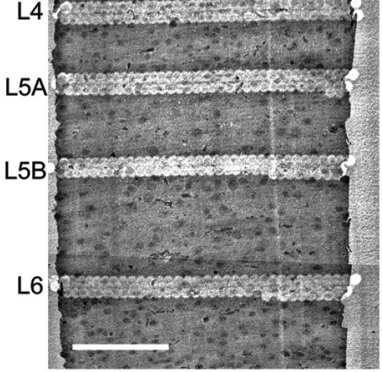

Figure 1. Translaminar isolation and analysis of D-row synapses from mouse barrel cortex. $A$, Schematic showing the dissection angle for visualization of all five barrel rows. $\boldsymbol{B}$, Example cytochrome oxidase-stained tissue from a P14 mouse showing all five barrel rows. Scale bar, $1 \mathrm{~mm}$. C, Example tissue section imaged under TEM. Scale bar, $100 \mu \mathrm{m}$. D, Example TEM image. Scale bar, $500 \mathrm{~nm}$. E, Mosaic showing examples of manually identified synapses for classifier training. Scale bar, $200 \mathrm{~nm}$.

of thin-tufted layer 5 (L5) pyramidal neurons arborizing in L1, has shown that there are experience-dependent alterations in spine properties (Holtmaat and Svoboda, 2009). At the same time, paired-cell recordings in S1 L2/3 pyramidal neurons indicate changes in connectivity strength between cells after altered sensory input (Cheetham et al., 2007; Wen and Barth, 2011). Whether these are exclusive, or even major, sites of change has not been examined systematically. These highly focused investigations have not addressed large-scale changes in circuit structure and function that might reveal coordinated altering of specific pathways by sensory or behavioral experience. As a first step toward this goal, we performed unbiased, high-throughput analysis of synapse properties over a large anatomical area to reveal additional loci of synaptic rearrangements.

We take advantage of an electron microscopy (EM) technique that uses ethanolic phosphotungstic acid (EPTA) to enhance visualization of synaptic structures while removing signal from other cellular structures (Bloom and Aghajanian, 1966, 1968) and then detect them with a machine-learning algorithm (Navlakha et al., 2013) to quantitatively compare synapse density and length across different experimental conditions. We use selective whisker stimulation, in which all but a single row of facial vibrissae have been removed, [single row experience (SRE); Wen et al., 2013], as a platform to test whether this unbiased, algorithmic approach can be used to detect experience-dependent changes in synapse organization across an entire cortical column.

Alterations in sensory input have been well established to induce synaptic plasticity and changes in sensory-evoked firing in S1 cortex of rodents (Fox, 1992; Diamond et al., 1994; Glazewski and Fox, 1996; Bender et al., 2006; Benedetti et al., 2009; Jacob et al., 2012). At the end of postnatal week 2 [postnatal day 14 (P14)], $24 \mathrm{~h}$ of SRE is associated with an increase in the synaptic strength of individual excitatory synapses from L4 to L3 neurons (Wen and Barth, 2011). This rapid plasticity ceases to occur after P15, although different forms and durations of sensory experience continue to drive synaptic changes and alterations in firing output throughout adult life (Trachtenberg et al., 2002; Cheetham et al., 2007; Wilbrecht et al., 2010; Jacob et al., 2012). Thus, we hypothesized that EPTA-assisted analysis of synaptic properties would be consistent with previous findings as well as reveal new sites of circuit change.

Initially, we examined synaptic density across the cortical column in 21 control, undeprived animals, acquiring $9775 \mathrm{im}$ ages representing $\sim 10 \%$ of the column height. Surprisingly, we observed that mean synapse density values could vary substantially across animals, a property that was most pronounced for superficial layers at P14 and was reduced in older animals (P18). We then examined whether $24 \mathrm{~h}$ of SRE in P14 animals could alter mean synapse density and length. We found that L2 and L6 were likely sites of change for synapse density and L3 and L5A were sites for changes in synapse length. Although SRE-dependent changes in synapse length were consistent with previous electrophysiological studies showing an increase in glutamatergic quantal amplitude between L4-L3 neurons (Wen and Barth, 2011), coordinated changes in synapse density and length across other cortical layers have not been, to our knowledge, reported previously. These data corroborate previous, highly focused anatomical and electrophysiological studies and stimulate new hypotheses about how altered sensory input can rewire neural circuits across the cortical column.

\section{Materials and Methods}

Animals. Wild-type C57BL/6 (Harlan origin, raised onsite) mice, of either sex, were birth-dated by daily cage checks. At P13, litters were divided into two groups: (1) a control group; and (2) an SRE group. Both control and SRE-treated animals were subjected to a brief period $(<1$ $\mathrm{min}$ ) of isoflurane anesthesia on the day of SRE treatment. For the SRE group, all but the D-row whiskers were plucked gently from the right side of the animal's face. All whiskers on the left side (ipsilateral) were fully removed (Glazewski et al., 2007; Wen et al., 2013). The control group was subjected to sham plucking by gently tugging at the whiskers with a pair of forceps. A total of $21 \mathrm{P} 14$ animals were used as sham-plucked controls, and 19 P14 animals were subjected to SRE. Eight control, sham-plucked P18 mice were used and also subjected to brief isoflurane anesthesia for consistency. Twenty-four hours later, the animals were killed by decapitation, and their brains were dissected out and immersion fixed in icecold 2.5\% glutaraldehyde (Electron Microscopy Sciences) in $0.1 \mathrm{M}$ phosphate buffer $(\mathrm{PB})$. After $24 \mathrm{~h}$ of glutaraldehyde fixation at $4^{\circ} \mathrm{C}$, brains were equilibrated with $\mathrm{PB}$ and $30 \%$ sucrose solution and stored at $4^{\circ} \mathrm{C}$ until sectioning.

Tissue preparation. To preserve the order of barrel column rows (A-E) in the hemisphere contralateral to the spared D-row whiskers, brains were cut at $45^{\circ}$ to the midline (Fig. $1 \mathrm{~A}$ ) for cryostat sectioning (Finnerty et al., 1999). Sections were cut at $50 \mu \mathrm{m}$ thickness and stored in PB. The A-E row of barrels was visualized by mitochondrial (cytochrome oxidase) staining (Land and Simons, 1985), and sections in which the D row could be unambiguously identified as the second-most medial barrel of five distinct barrels in the specimen were selected for manual tissue dissection (Fig. $1 B$ ). In only two to three $50-\mu \mathrm{m}$-thick sections were all rows unambiguously present; specimens without five clear barrels present were excluded from additional analysis. Because barrels within the posteromedial barrel subfield are larger, ranging from 150 to $300 \mu \mathrm{m}$ in diameter, visualization of a clear cytochrome oxidase signal in the second-most medial barrels likely indicated that the section was from the 
middle of the D barrel. Dissected columns were typically 200-300 $\mu \mathrm{m}$ wide and spanned the pial surface to the white matter, and only one column per animal was evaluated (Fig. 1C). When comparisons between EPTA-EM and traditional EM staining were made, tissue from adjacent $50-\mu \mathrm{m}$-thick sections from the same animal were examined.

EM tissue preparation. For EPTA staining of synapses (Bloom and Aghajanian, 1966, 1968), the dissected 50- $\mu$ m-thick section was washed three times in distilled water ( $5 \mathrm{~min}$ each), followed by incubation in $0.02 \% \mathrm{NaOH}$ in water for $10 \mathrm{~min}$. The tissue was dehydrated with an ascending series of ethanol baths $(25,50,70,80,90$, and 100\%; 5 min each). A $1 \%$ phosphotungstic acid (PTA; Ladd Research) solution was prepared in $100 \% \mathrm{EtOH}$. A critical step for this solution was the addition of a tiny amount of water, via a 95\% ethanol solution (7 $\mu \mathrm{l}$ of $95 \%$ ethanol per $1000 \mu \mathrm{l}$ of PTA solution, for a final $\mathrm{H}_{2} \mathrm{O}$ concentration of $0.035 \%)$. The dehydrated tissue was moved into the PTA solution and incubated at room temperature, with shaking, for $1 \mathrm{~h}$. PTA was washed from the sample with two changes of $100 \%$ ethanol. Next, propylene oxide (PO; Electron Microscopy Sciences) was used as a transitional solvent, in which the first change of $\mathrm{PO}$ was on ice, and then the specimen was infiltrated with Spurr embedding resin (Ted Pella) and then polymerized at $60^{\circ} \mathrm{C}$ for $48 \mathrm{~h}$. Finally, $100 \mathrm{~nm}$ sections were cut using a diamond knife (Delaware Diamond Knife) on an Ultracut-E ultramicrotome (Riechert Jung) and were picked up using single-slot copper grids (Electron Microscopy Sciences).

For conventional EM imaging, the dissected 50- $\mu$ m-thick sections were incubated with $1 \% \mathrm{OsO}_{4}$ in $\mathrm{PBS}$ for $1 \mathrm{~h}$, followed by three distilled $\mathrm{H}_{2} \mathrm{O}$ washes and then dehydrated and embedded in Spurr resin as described above. Sections were cut at $100 \mathrm{~nm}$ and exposed to $0.89 \%$ lead citrate solution in water for $1 \mathrm{~h}$ (Reynolds, 1963) before imaging.

Image acquisition. Samples were viewed on a Hitachi H-7100 transmission electron microscope (TEM; Hitachi High Technologies America) operating at $75 \mathrm{kV}$. Digital images were obtained using a Kodak Megaplus 1.6i camera and the AMT Advantage 10 CCD Camera System (Advanced Microscopy Techniques) and NIH Image software. The electron beam was scanned across each cortical layer parallel to the pial surface and non-overlapping images $(8-10 \mu \mathrm{m}$ apart) were obtained in a continuous manner (Fig. 1C). Approximately 100 images, each representing a $4.31 \times 4.31 \mu \mathrm{m}$ region were captured for each layer (Fig. $1 D$ ).

Laminar identity. After mounting on copper grids, tissue specimens exhibited $\sim 25 \%$ shrinkage. This was determined by comparing the column height $(H)$ as marked by the separation between fiduciary landmarks, namely the pia and an angular cut that was manually made underneath L6, for resin-embedded specimens compared with the 100$\mathrm{nm}$-thick mounted section. Laminar depths were determined based on previous reports (Lefort et al., 2009), and images were taken after adjusting the depths for the relative shrinkage for each sample (the specimen height from the embedded sample, compared with the 100-nm-thick section cut from the embedded sample for imaging). Laminar depths for imaging were as follows: (1) L1, $50 \mu \mathrm{m}$; (2) L2, $125 \mu \mathrm{m}$; (3) L3, $325 \mu \mathrm{m}$; (4) L4, $500 \mu \mathrm{m}$; (5) L5A, $600 \mu \mathrm{m}$; (6) L5B, $725 \mu \mathrm{m}$; and (7) L6, $900 \mu \mathrm{m}$.

Shrinkage Factor $(s)=H_{\text {TEM }} / H_{\text {resin }}$, where $H_{\text {TEM }}$ was the distance between the pia and L6 landmark under TEM, and $H_{\text {resin }}$ was the distance between pia and L6 landmark in resin.

Adjusted depth of layers $(d)=D \times s$, where $D$ was the depth from previous reports (Lefort et al., 2009), and $s$ was the shrinkage factor.

Cytoarchitectural features, including L1 as a cell-sparse region adjacent to a dense layer of cell bodies representing L2, L4 with characteristic smaller granular cell nuclei, and L5A with the emergence of larger cell nuclei adjacent to L4, were also used to corroborate laminar identity. Overall cortical thickness did not change during the developmental window examined (P14 L1-L6 thickness, $1.16 \pm 0.06 \mathrm{~mm}, n=4$ versus P18, $1.22 \pm 0.02 \mathrm{~mm}, n=3$; depth of layer 4 from the pia, P14, $0.48 \pm 0.07$ $\mathrm{mm}$ versus $\mathrm{P} 18,0.46 \pm 0.03 \mathrm{~mm}$; all values mean $\pm \mathrm{SD}$ ).

Image analysis. Images were analyzed using custom-written software in MATLAB (MathWorks). First, the contrast of each image was enhanced using a contrast-limiting adaptive histogram equalization algorithm (Zuiderveld, 1994), and each image was binarized using a single, sample-independent threshold. The remaining pixels were linked into connected segments, or objects, in each image. Objects were filtered to exclude very small $\left(<5.5 \times 10^{3} \mathrm{~nm}^{2}\right)$ or very large $\left(>66 \times 10^{3} \mathrm{~nm}^{2}\right)$ components, because these were unlikely to be synapses. A $75 \times 75$ pixel square patch was isolated around the centroid of the selected objects so as to use the features of the immediate neighborhood of the objects for better classification. To eliminate variability attributable to variable orientations of the objects, all of them were rotated using a Hough transformation so that their major axis were oriented vertically (Navlakha et al., 2013). Synapses were identified based on the following features: (1) the presence of a highly electron-opaque band, representing the postsynaptic membrane (Bloom and Aghajanian, 1966); (2) the presence of either circular electron-opaque structures or another less intense electronopaque band arranged parallel to the postsynaptic membrane; (3) a well defined gap between the postsynaptic and presynaptic structures representing the synaptic cleft; and (4) no more than two electron-opaque bands arranged in parallel (often found in mitochondrial structures). The surrounding box was cropped down and objects were identified within a $61 \times 61$ pixel $(256 \times 256 \mathrm{~nm})$ square patch around its centroid. A support vector machine machine-learning algorithm was used to classify objects as synapses based on texture- and shape-based features (Navlakha et al., 2013). The classifier was trained using 1665 manually identified synapse examples (Fig. $1 E$ ) and 10,441 nonsynapse examples. Given a candidate object, the classifier assigned a score between 0 and 1 representing the likelihood that this object represented a synapse based on its features. To use the classifier on new images in this study and to account for natural heterogeneity in sample quality (tissue staining, microscope lightning, etc.), a randomly selected $10 \%$ of the images from each sample were labeled manually to generate a test dataset of synapses and nonsynapses. Classifier performance for each sample, $S$, was evaluated on the test dataset (generated from $S$ ), to determine the appropriate confidence threshold to apply to all images in $S$. The threshold used was selected so that the positively labeled set of objects (synapses) identified by the classifier for each sample had a recall value of $50 \%$ (half of the manually identified synapses had a score above the threshold selected), where recall is defined as follows: Recall $=\mathrm{TP} /(\mathrm{TP}+\mathrm{FN})$, where $\mathrm{TP}$ is true positives, and $\mathrm{FN}$ is false negatives.

Given a threshold leading to a $50 \%$ recall, we computed the precision for each sample, where precision is the probability that a predicted synapse was truly a synapse in the test dataset: Precision $=\mathrm{TP} /(\mathrm{TP}+\mathrm{FP})$, where TP is true positives, and FP is false positives.

Computed precision values for each sample layer ranged from 11 to $100 \%$ (mean of $75 \%$ among control and SRE-treated animals) at P14, whereas they ranged from 30 to $100 \%$ (mean of $73 \%$ among control P18 animals). To calculate synapse density, we adjusted synapse density values to take into account potential FP synapses that the classifier exhibited at $50 \%$ recall. Final estimates of synapse density were then multiplied by 2 (to account for the recall value) to estimate actual synapse numbers: Final synapse density $=$ Synapse density reported by the algorithm $\times$ Precision of algorithm for that sample $\times 2$.

Synapse length measurements were obtained from each object by fitting an ellipse to the object (i.e., the synapse) and calculating the major axis length (Navlakha et al., 2013). Synapse curvature was not corrected for; thus, synapse length measurements may be underestimated. For synapse length measurements, it was critical to ensure that only TP, i.e., bona fide synapses, were used for our calculations. Therefore, only samples that had precision values $>75 \%$ were used for these calculations. Consequently, the number of animals included in the analysis could vary by layer. The synapse detection algorithm (and human observers) could not distinguish between excitatory and inhibitory synapses. Thus, the changes reported in this study encompass all classes of synapses.

Whole-cell recording. Animals were anesthetized with isoflurane and decapitated. Acute brain slices at $350 \mu \mathrm{m}$ thickness were prepared by an "across-row" protocol (Finnerty et al., 1999). Slices were vibratome sectioned in artificial CSF at $2-6^{\circ} \mathrm{C}$ composed of the following (mM): 119 $\mathrm{NaCl}, 2.5 \mathrm{KCl}, 2.5 \mathrm{CaCl}_{2}, 1.3 \mathrm{MgSO}_{4}, 1 \mathrm{NaH}_{2} \mathrm{PO}_{4}, 26.2 \mathrm{NaHCO}_{3}$, and 11 glucose (equilibrated with $95 \% \mathrm{O}_{2} / 5 \% \mathrm{CO}_{2}$ ). Slices were maintained and whole-cell recordings were performed at room temperature. Somata of upper L2 pyramidal neurons ( $\leq 175 \mu \mathrm{m}$ from the pial surface) in the D-row column were targeted for whole-cell recording with borosilicate glass electrodes with a resistance of 6-8 M . Electrode internal solution 
Table 1. P14 versus $P 18$ synapse densities

\begin{tabular}{|c|c|c|c|c|}
\hline & \multicolumn{2}{|c|}{ P14 control } & \multicolumn{2}{|c|}{ P18 control } \\
\hline & $\begin{array}{l}\text { Animals } \\
(n)\end{array}$ & $\begin{array}{l}\text { Mean } \pm \text { SD } \\
\left(\text { synapses/ } \mu \mathrm{m}^{2} \text { ) }\right.\end{array}$ & $\begin{array}{l}\text { Animals } \\
(n)\end{array}$ & $\begin{array}{l}\text { Mean } \pm S D \\
\left(\text { synapses } / \mu \mathrm{m}^{2}\right)\end{array}$ \\
\hline $\mathrm{L} 1^{*}$ & 14 & $0.246 \pm 0.044$ & 7 & $0.356 \pm 0.081$ \\
\hline $\mathrm{L}^{\dagger}$ & 20 & $0.241 \pm 0.062$ & 8 & $0.328 \pm 0.060$ \\
\hline L3 & 20 & $0.253 \pm 0.089$ & 8 & $0.330 \pm 0.050$ \\
\hline L4 & 19 & $0.231 \pm 0.084$ & 8 & $0.303 \pm 0.041$ \\
\hline L5A & 9 & $0.249 \pm 0.071$ & 8 & $0.309 \pm 0.052$ \\
\hline L5B & 9 & $0.217 \pm 0.035$ & 8 & $0.276 \pm 0.076$ \\
\hline L6 & 9 & $0.219 \pm 0.052$ & 8 & $0.201 \pm 0.054$ \\
\hline
\end{tabular}

*Significant increase at P18, $p=0.0007$

${ }^{\dagger}$ Significant increase at P18, $p=0.0022$

Table 2. P14 control versus $24 \mathrm{~h}$ SRE synapse densities

\begin{tabular}{|c|c|c|c|c|}
\hline & \multicolumn{2}{|c|}{ P14 control } & \multicolumn{2}{|c|}{ P14 24h SRE } \\
\hline & $\begin{array}{l}\text { Animals } \\
(n)\end{array}$ & $\begin{array}{l}\text { Mean } \pm \text { SD } \\
\left(\text { synapses/ } \mu \mathrm{m}^{2}\right)\end{array}$ & $\begin{array}{l}\text { Animals } \\
(n)\end{array}$ & $\begin{array}{l}\text { Mean } \pm S D \\
\left(\text { synapses } / \mu \mathrm{m}^{2}\right)\end{array}$ \\
\hline L1 & 14 & $0.246 \pm 0.044$ & 15 & $0.232 \pm 0.121$ \\
\hline L2 & 20 & $0.241 \pm 0.062$ & 18 & $0.287 \pm 0.089$ \\
\hline L3 & 20 & $0.253 \pm 0.089$ & 18 & $0.273 \pm 0.088$ \\
\hline L4 & 19 & $0.231 \pm 0.084$ & 19 & $0.247 \pm 0.081$ \\
\hline L5A & 9 & $0.249 \pm 0.071$ & 9 & $0.228 \pm 0.067$ \\
\hline L5B & 9 & $0.217 \pm 0.035$ & 9 & $0.194 \pm 0.060$ \\
\hline L6 & 9 & $0.219 \pm 0.052$ & 9 & $0.161 \pm 0.054$ \\
\hline
\end{tabular}

was composed of the following (in $\mathrm{mm}$ ): 130 cesium, 10 HEPES, 0.5 EGTA, $8 \mathrm{NaCl}$, $4 \mathrm{Mg}$-ATP, and 0.4 Na-GTP, pH 7.25-7.30 (290-300 mOsm), containing trace amounts of Alexa Fluor-568. Pyramidal cell identity was confirmed after the recording session by pyramidal soma morphology and the presence of dendritic spines. Only cells with $R_{\text {series }}$ $\leq 40 \mathrm{M} \Omega$ and $R_{\text {input }} \geq 200 \mathrm{M} \Omega$, in which changes in either measurement were $<30 \%$ were included for analysis. Electrophysiological data were acquired by Multiclamp 700A (Molecular Devices) and a National Instruments acquisition interface. The data was filtered at $3 \mathrm{kHz}$, digitized at $10 \mathrm{kHz}$, and collected by Igor Pro 6.0 (Wavemetrics).

Recordings were performed with $0.5 \mu \mathrm{M}$ tetrodotoxin (Sigma) in the bath solution, and L2 pyramidal neurons were voltage clamped at -70 or $10 \mathrm{mV}$ for isolation of miniature EPSCs (mEPSCs) and mIPSCs, respectively. Isolated, asynchronous events were selected manually and analyzed using Minianalysis software (Synaptosoft). The detection threshold for events was set at $2 \times$ root mean square noise (usually $\sim 4-5 \mathrm{pA}$ ), and data were filtered with a low-pass filter at $1 \mathrm{kHz}$.

Statistics. Mean synapse density for each animal was calculated using the "final synapse density" value measured for individual layers. These values were averaged across all animals in a group to provide a group mean for each layer (Tables 1,2). All values are presented as mean \pm SEM unless indicated. To assess significance across ages or whisker experience, we used a unpaired, two-tailed $t$ test to compare individual layers, followed by a Benjamini-Hochberg correction for controlling false discovery rate $(d)$ with significance set at $p=0.5$ for multiple comparisons. In this method, all the $p$ values $\left(p_{1}, \ldots, p_{n}\right)$ from $n$ comparisons $(n=7$ for this study, because the analyses were performed for 7 cortical layers) are arranged in ascending order, and all $p$ values $\left(p_{1}, \ldots, p_{k}\right)$ are declared significant, where $k$ denotes the largest $p$ value index $i$ for which $p_{i} \leq d / n$.

mEPSC and mIPSC amplitude and frequency was compared for animal (not cell) averages across conditions using a two-way ANOVA, followed by a post hoc Tukey's HSD test.

For analysis of synapse length, length measurements from all identified synapses from samples with a precision $\geq 75 \%$ were included but weighted to ensure that the population distribution was not biased by synapses from any one sample. For differences in mean length of synapses, a two-way ANOVA for mean synapse length across conditions and layers was performed. For cumulative histograms of synapse lengths in any given layer, we used a two-sample Komolgorov-Smirnov (K-S) test, with Benjamini-Hochberg correction for multiple comparisons.

\section{Results \\ Animal-to-animal variability in synapse density measurements}

To understand how synapse properties might vary across a population of control animals - a necessary analysis before applying this method across a variety of experimental conditions-we initially focused on EPTA-EM data collected from P14 animals. Synapse density and length measurements for 16,240 synapses were made for each cortical lamina, in 21 animals from eight different litters. Overall, mean density calculated across all animals in the P14 undeprived animal dataset was similar across layers (Fig. 2A), a developmental characteristic consistent with previous studies (Huttenlocher and Dabholkar, 1997).

One advantage of a semiautomated synapse detection algorithm is that it enables sampling of broad areas of the cortex-an entire cortical column in a laminar-specific manner-to obtain large numbers of example synapses. Do these large datasets reduce experimental variability, either within a sample or across samples? We found that the large number of synapses collected for each animal was sufficient to reduce variability from subsampling (Fig. 2B). As expected, as the image dataset expanded, the SD of mean synapse density decreased, until at least 50 images were included (Fig. 2C). Thus, 90-120 images were typically used to calculate synapses density from each layer.

Mean synapse density values for individual animals at P14 were highly variable. This did not appear to stem from our algorithmic detection method, because a direct comparison of synapse density identified by either EPTA-staining or conventional EM (from adjacent sections from the same tissue specimen) showed a high correlation between these values (Fig. $2 D-F$ ). EPTA-assisted semiautomated synapse detection typically classified more synapses than visually identified synapses from conventional EM images (Fig. $2 D$ ), a result that may be attributed to better detection of small synapses.

Did across-animal variability in mean synapse density come from differences in sample preparation? For example, the classifier performance in samples in which background staining was high might be impaired, with more FP synapse "objects." Indeed, precision values varied widely across tissue samples. We compared synapse detection by the algorithm with manual detection from the same images and found that synapse densities were correlated significantly using the two approaches $(r=0.81)$ and that classifier performance measured by precision was unrelated to final density values (Fig. $2 G$ ).

To determine whether the high variability observed across animals could be attributed to differences in biological factors resulting from animal litter (for example, resulting from small variations in birth-dating estimates, litter size, or maternal care profile; Seelke et al., 2015), we compared synapse density values for control P14 animals from the same litter (Fig. $2 \mathrm{H}$, example litter). In general, we found that animals from the same litter had more similar synapse density values, although the same layer compared across animals from the same litter could vary up to twofold in synapse density (Fig. 2I). Thus, litter identity could explain some of the variation observed, although overall we conclude that small differences in litter birth-dating or gestation time were not sufficient to fully explain the observed overall variation.

\section{Synapse density increases in superficial layers from P14 to P18}

Previous studies have shown that synapse density in the neocortex increases during postnatal development, peaking around the end of postnatal week 3 (Micheva and Beaulieu, 1996; De Felipe 
A

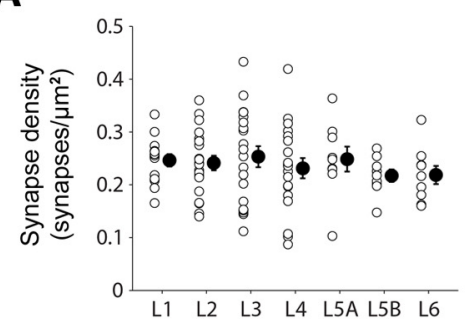

D

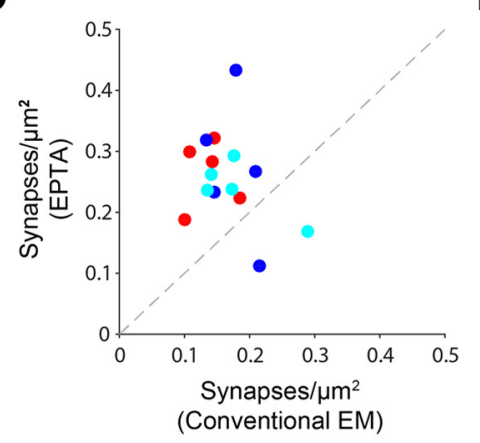

G

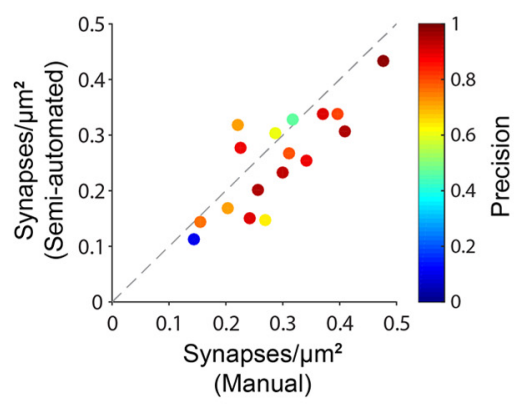

I

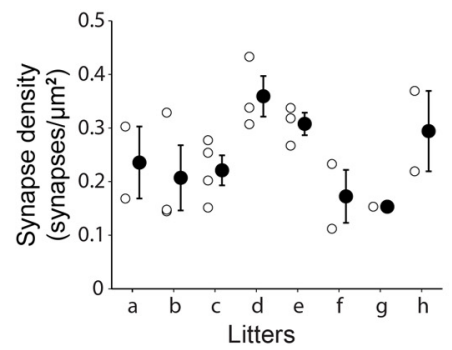

B

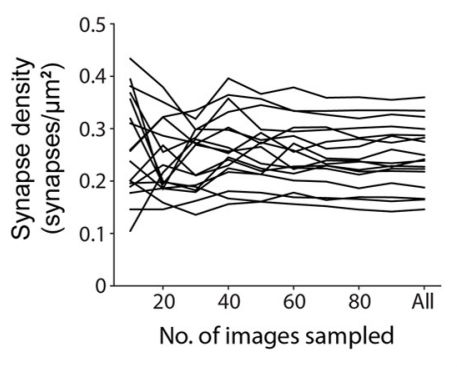

E

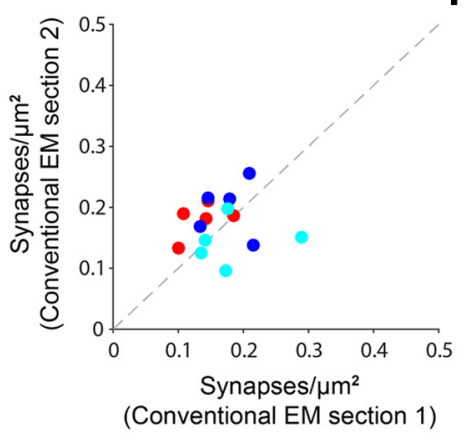

H
C

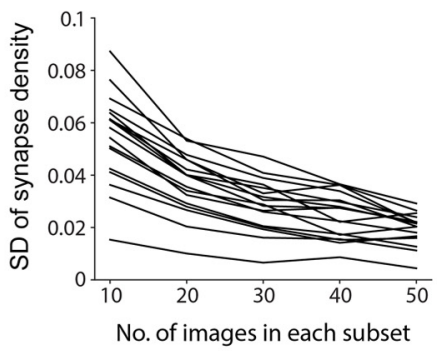

F

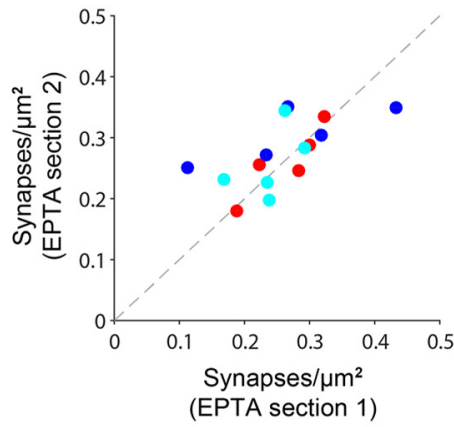

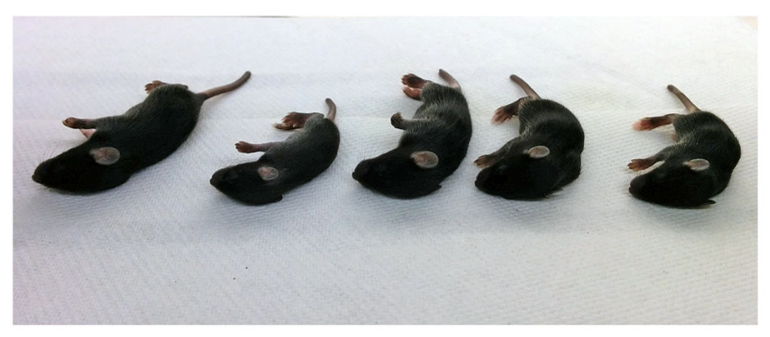

Figure 2. Biological contributions to across-animal variability in synapse density. $\boldsymbol{A}$, Mean synapse density at P14 by layer for each animal (open circles) and across all animals (filled circles). $\boldsymbol{B}$, Calculated mean synapse density values become less variable as image number increases. L3 values shown for example. C, The SD of mean synaptic density is reduced for larger (non-overlapping) image sets. L3 values shown for example. D, EPTA-assisted semiautomated synapse detection compared with manual synapse detection from conventional EM for the same animal in L2 (red), L3 (blue), and L4 (cyan). $\boldsymbol{E}$, Manually identified EM synapse density values are consistent across sections from the same animal for L2 (red), L3 (blue), and L4 (cyan). $\boldsymbol{F}$, As in $\boldsymbol{E}$ but for algorithm-identified synapses from EPTA-stained images. G, Manual versus algorithm-identified synapse densities for L3 samples from each P14 animal. Color represents the precision of the algorithm for that sample. Values were significantly correlated, using Pearson's correlation coefficient, $p=0.0001$. $\boldsymbol{H}$, P14 mice (anesthetized) from the same litter show differences in body size. $I$, Variability in synapse density cannot be attributed to different litters. Mean synapse density for individual animals (open circles) grouped by litter ( $a-h$ ) and the litter group mean (filled circles). L3 values shown for example.

et al., 1997; White et al., 1997). We selected P18 as a comparative time point, soon after the closure of the critical period for rapid, experience-dependent changes in synaptic strength (Wen and Barth, 2011). At P18, we found that L1 showed the highest developmental increase in synaptic density, with a significant, nearly $50 \%$ increase from P14 (Fig. $3 A, B$; Table 1). Layer 2 also showed a significant, $36 \%$ increase in density (Table 1 ). Infragranular layers showed a much smaller increase, with a $24 \%$ increase in
L5A and a $27 \%$ increase in $\mathrm{L} 5 \mathrm{~B}$, and a small $8 \%$ decrease in L6, differences that did not meet statistical significance (Table 1).

Across-animal variability in synapse density was reduced in animals aged P18, suggesting that it might have a developmental component. Mean coefficient of variation (CV, or SD/mean) decreased in $\mathrm{P} 18$ animals (Fig. 3C). The CV for $\mathrm{L} 3$ and $\mathrm{L} 4$ declined by $>50 \%$ from P14 to P18 despite the fact that the P18 group consisted of fewer animals (Fig. $3 \mathrm{C}$ ). These data support the hy- 
A

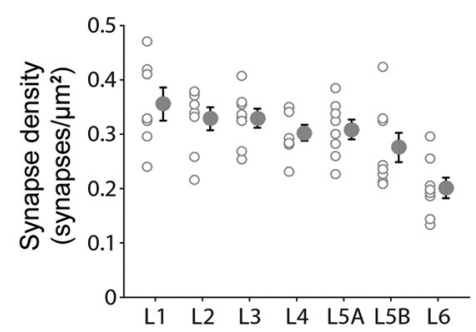

B

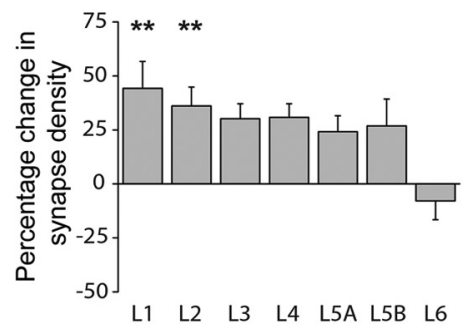

C

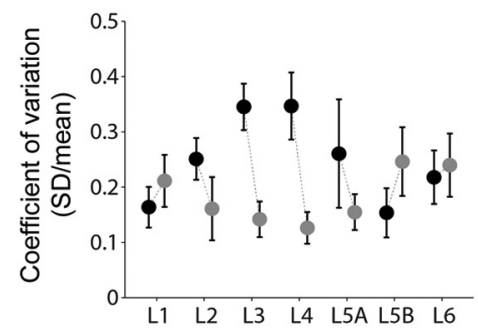

Figure 3. Synapse density increases in superficial layers at P18. $\boldsymbol{A}$, Mean synapse density at P18 by layer for individual animals (open circles) and across all animals (filled circles). $\boldsymbol{B}$, Mean percentage change in synapse density in P18 animals, normalized to the P14 mean for each layer. Asterisks indicate a significant difference for L1 and L2 only. C, The CV of synapse density for each layer for P14 (black) and P18 (gray) animals. Error bars indicate SD calculated by bootstrapping for 200 iterations.

pothesis that the high variability observed at P14 might be attributed to developmental asynchrony across different animals that may be pronounced at this stage (Fig. $2 \mathrm{H}$ ).

Our data suggest that synapse density is not a tightly constrained property of cortical circuits, especially during circuit maturation. The large number of animals examined in this study enabled us to observe this developmentally regulated feature of cortical organization and might explain why previous studies that typically focus on less than three animals per group (Micheva and Beaulieu, 1996; De Felipe et al., 1997) have not identified this phenomenon. Analysis of stimulus-induced changes in synapse density during development may require analysis of a large number of animals within each experimental group.

\section{Synapse length changes during cortical development}

Our semiautomated analysis also enabled us to capture each identified synapse "object" and then evaluate its morphological properties (Fig. 1E). Synapse diameter is correlated with AMPAR content of the synapse (Kharazia and Weinberg, 1999), and studies in adult animals indicate a close correspondence between EMassessed synapse ultrastructure and synaptic strength (Cheetham et al., 2014). We used this rich dataset to calculate mean synapse length across layers, animals, and over the 4 day developmental window between P14 and P18 (Fig. 4; Table 3).

Mean synapse length for animals of a given age was highly consistent, varying by a maximum of only $10 \%(\mathrm{CV}=0.05)$ in any given layer (for example, at P14, the maximum mean synapse length in L2 was $0.235 \mu \mathrm{m}$ and a minimum of $0.211 \mu \mathrm{m}$; Fig. $4 A, B)$. Mean synapse length varied across layers: at P14, L2 and L3 had slightly shorter synapses than other layers, and L6 had the longest synapses (Fig. 4C-E; Table 3). This trend was also visible at P18, with shorter synapses in L2 and long synapses in L6 (Fig. $4 F, G$; Table 3).

Notably, L3 and L5B exhibited a significant increase in mean synapse length from P14 to P18 (Fig. 4G-J; Table 3). Thus, we predict that inputs specific to L3, for example from L4, or between L3 neurons (Petreanu et al., 2009), may be selectively strengthened during this short developmental window. Inputs to L5B, such as thalamic inputs from the ventroposterior medial nucleus (Wimmer et al., 2010; Oberlaender et al., 2012), between specific subsets of L5 pyramidal or inhibitory neurons (Silberberg and Markram, 2007) or from L3 pyramidal neurons that innervate L5B (Lefort et al., 2009), may also be subjected to developmental increases in synaptic strength.

\section{Altered whisker input changes synaptic density site specifically}

To determine whether synapse density might be altered by imbalanced sensory input, mice were subjected to bilateral whisker removal, sparing only the D row on the right side (SRE; Fig. 5A). These experiments focused on $24 \mathrm{~h}$ deprivations initiated at P13, because previous work has established that rapid, pathwayspecific synaptic potentiation synapses is pronounced at this age (Wen and Barth, 2011). Analysis of 16,449 synapses in 19 animals from eight litters suggested that the distribution of synapse density across all layers was altered by SRE (Fig. 5B; Table 2), with an increase in superficial and a decrease in deep layers compared with control, undeprived littermates, in which mean synapse density across layers was similar (Fig. 2A). In particular, L2 showed a 19\% increase and L6 showed a 27\% decrease after SRE (Fig. 5D; Table 2). No differences were statistically significant after Benjamini-Hochberg correction.

Because we observed that a substantial portion of the variance between animals could be attributed to the specific litter from which an individual animal came, we investigated whether there might be any systematic differences between control and SREtreated animals from a given litter (Fig. 6). In all cases, SREtreated animals had at least one littermate control, and, in many cases, we had several control and SRE-treated animals within the same litter. Thus, we compared synapse density means for each condition, grouped by litter. Only for layer 2 did we observe a notable difference, in which in six of eight litters the synapse density increased after SRE. However, this difference did not meet criterion for statistical significance after Benjamini-Hochberg correction.

A cumulative histogram plot of synapses per image, calculated from all animals per group, revealed a significant shift in the distribution of synaptic densities for each layers after SRE (data not shown). Consistent with the differences in mean density, the greatest shifts were observed in L2 and L6, in which SRE was associated with an increase in the density of synapses per image in L2 and a decrease in L6.

\section{SRE enhances mEPSC frequency in L2}

Previous imaging studies in L1-L2 have shown that L2 dendritic spines and the apical dendrites of L5 pyramidal neurons are changed during learning or altered sensory input (Lendvai et al., 2000; Trachtenberg et al., 2002; Zuo et al., 2005; Holtmaat et al., 2006; Holtmaat and Svoboda, 2009; Wilbrecht et al., 2010; Kuhlman et al., 2014). The connection probability of L2 pyramidal cells, synapse that are typically localized to L2 (Feldmeyer et al., 2006), can also be reduced by sensory deprivation (Cheetham et al., 2007). These studies have been performed using a variety of whisker-dependent behaviors, deprivation patterns, and animal ages, making comparisons between studies and comprehensive analysis across layers difficult.

Identification of experience-dependent changes for synapses located within L2 limits possible networks that might be altered. 
A

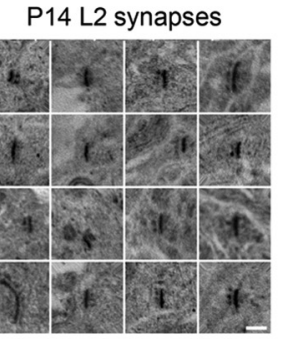

B

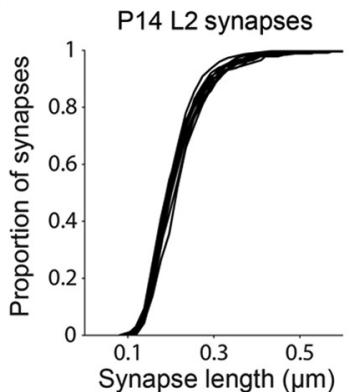

P14

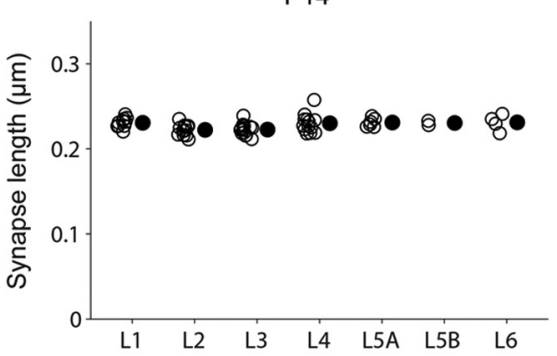

C

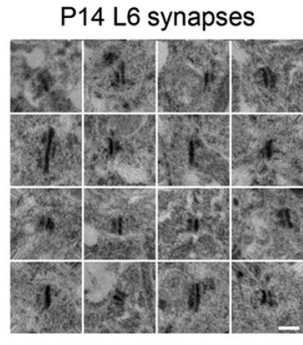

D

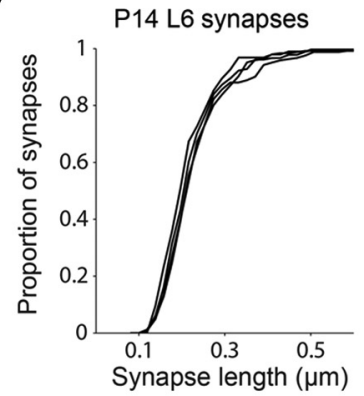

F

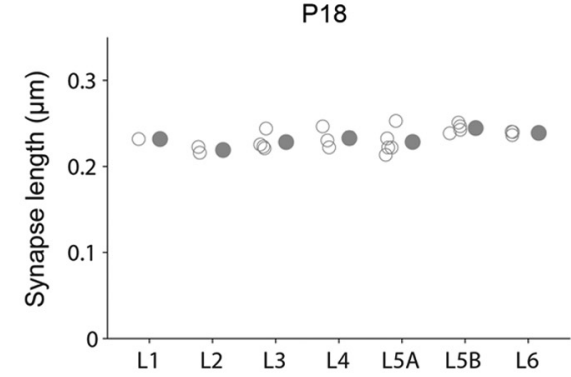

G

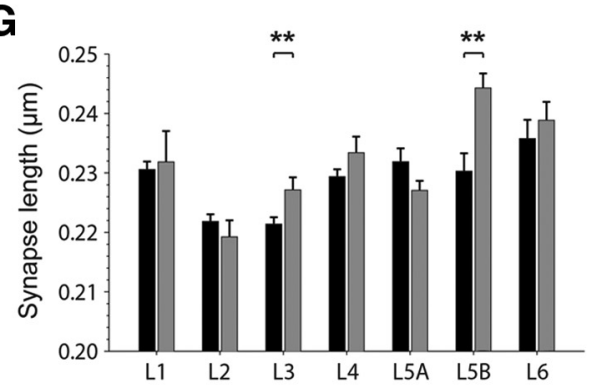

H

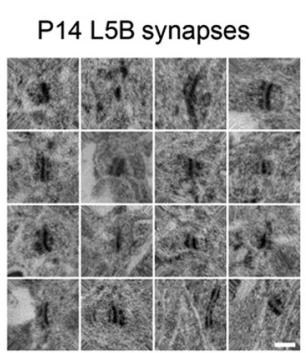

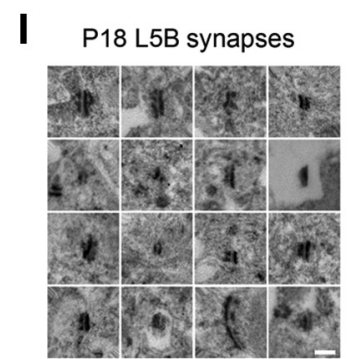

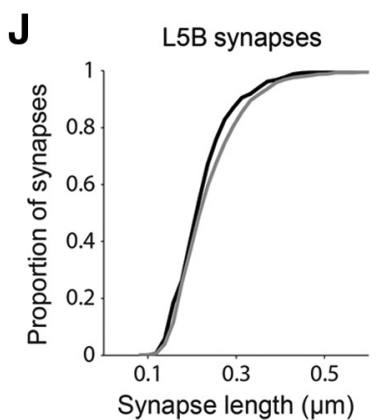

Figure 4. Mean synapse length increases over postnatal week 3. $\boldsymbol{A}$, Example synapses from L2 of the D barrel column in P14 control animals. Scale bar, $200 \mathrm{~nm}$. $\boldsymbol{B}$, Cumulative distribution histograms of synapse length for L2 for all P14 control animals. C, As in $\boldsymbol{A}$ but for L6 at P14. Scale bar, $200 \mathrm{~nm}$. D, As in $\boldsymbol{B}$ but for L6 at P14. E, Synapse lengths are constant across animals. Individual animal mean length (open circles) and group mean (filled circles) shown by layer at P14. F, As in E but at P18. G, P14-P18 comparison of the mean synapse length for each layer. Mean synapse length in L3 and L5B is significantly larger in P18 animals. See Table 3 for group $n$. $\boldsymbol{H}$, As in $\boldsymbol{A}$ but for L5B at P14. I, As in $\boldsymbol{A}$ but for L5B at P18. J, Cumulative histogram comparing L5B synapse length at P14 (black) and P18 (gray). $p=0.072$ with two-sample K-S test.

Table 3. $P 14$ versus $P 18$ synapse lengths

\begin{tabular}{|c|c|c|c|c|c|c|}
\hline & \multicolumn{3}{|c|}{ P14 control } & \multicolumn{3}{|c|}{ P18 control } \\
\hline & $\begin{array}{l}\text { Synapses } \\
(n)\end{array}$ & $\begin{array}{l}\text { Animals } \\
(n)^{\S}\end{array}$ & $\begin{array}{l}\text { Mean } \pm S D \\
(\mu \mathrm{m})\end{array}$ & $\begin{array}{l}\text { Synapses } \\
(n)\end{array}$ & $\begin{array}{l}\text { Animals } \\
(n)^{\S}\end{array}$ & $\begin{array}{l}\text { Mean } \pm S D \\
(\mu \mathrm{m})\end{array}$ \\
\hline L1 & 2917 & 11 & $0.231 \pm 0.072$ & 393 & 1 & $0.232 \pm 0.103$ \\
\hline L2 & 3336 & 13 & $0.222 \pm 0.069$ & 652 & 2 & $0.219 \pm 0.071$ \\
\hline L3* & 3647 & 14 & $0.221 \pm 0.070$ & 1429 & 4 & $0.227 \pm 0.080$ \\
\hline L4 & 3595 & 13 & $0.229 \pm 0.073$ & 956 & 3 & $0.233 \pm 0.083$ \\
\hline L5A & 1448 & 6 & $0.232 \pm 0.083$ & 1973 & 5 & $0.227 \pm 0.072$ \\
\hline $\mathrm{L}^{+} \mathrm{B}^{+}$ & 531 & 2 & $0.230 \pm 0.069$ & 1120 & 4 & $0.244 \pm 0.082$ \\
\hline L6 & 766 & 4 & $0.234 \pm 0.080$ & 725 & 3 & $0.239 \pm 0.083$ \\
\hline
\end{tabular}

*Significant increase at $\mathrm{P} 18, p=0.011$.

${ }^{\dagger}$ Significant increase at P18, $p=0.0007$.

${ }^{\S}$ Number of animals reflects only those animals in which the algorithm had a precision $\geq 0.75$.

The increase in synapse density in L2 might arise from a variety of sources, including the following: (1) an increase in connections between local L2 neurons or between L3 and L2 neurons; (2) in connections between L5 and L2 neurons (Frick et al., 2008; Oberlaender et al., 2011); (3) from the thalamus to L2 neurons; (4) from contralateral S1 neurons; or (5) between L2 neurons and local inhibitory neurons (Feldmeyer et al., 2006; Cheetham et al., 2007; Lefort et al., 2009; Petreanu et al., 2009; Fino and Yuste, 2011; Jouhanneau et al., 2014). In addition, synapses between neurons with cell bodies in other layers or brain areas might be located within L2, such as thalamic or M1 inputs onto L5 apical dendrites.

Because L2-L2 recurrent connectivity is one of the major sources of input to L2 neurons (Lefort et al., 2009) and because these inputs are strengthened after SRE (Wen and Barth, 2011), we hypothesized that increases in L2 synapse density after SRE might be detected as an increase in mEPSCs. Electrophysiological recordings might also enable us to examine changes in inhibitory and excitatory synapses, which the EPTA method could not easily differentiate (Hildebrandt et al., 2011).

Whole-cell patch-clamp recordings targeted to L2 pyramidal neurons were performed for control and SRE-treated animals (Fig. 7A). mEPSCs and mIPSCs were collected. In SRE animals, mean mEPSC frequency was $2.799 \pm 0.914 \mathrm{~Hz}$, approximately twofold greater than that observed in control animals (1.532 \pm $0.547 \mathrm{~Hz}$ ), a difference that was highly significant (Fig. $7 F$ ). In contrast, mIPSC frequency was not altered between the two con- 
A
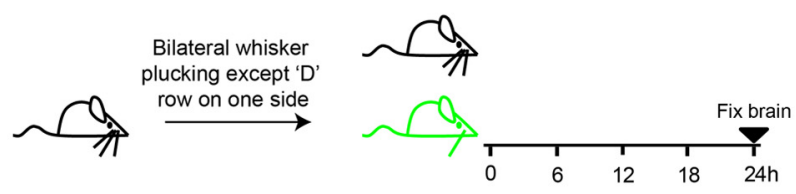

B

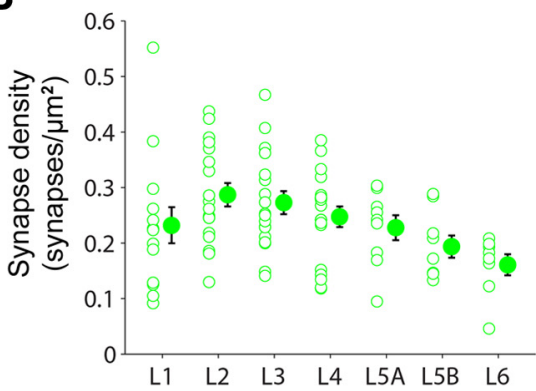

C

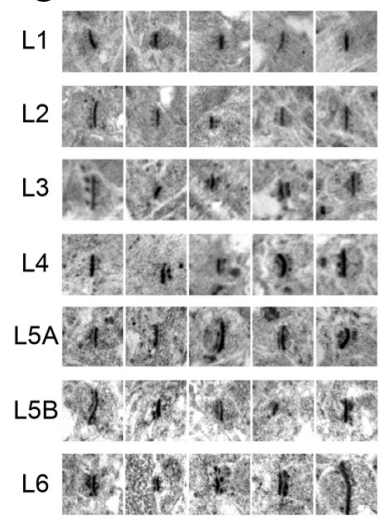

Control synapses
D

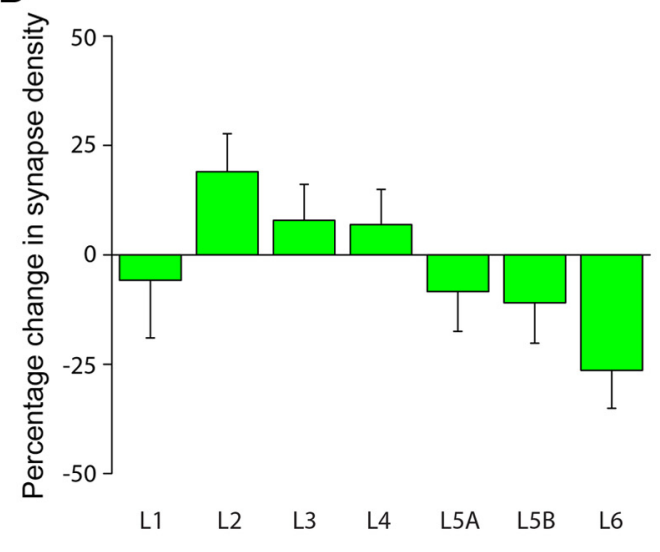

$\mathbf{E}$

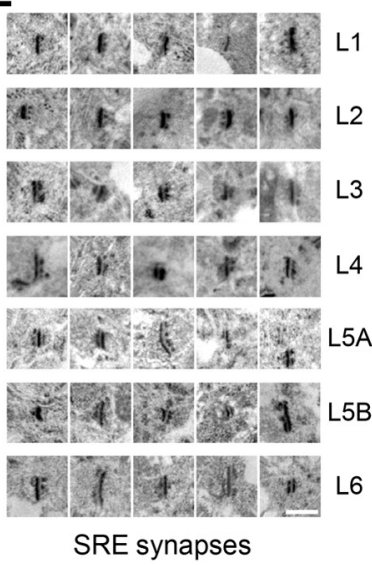

Figure 5. Laminar alterations in synapse density after selective whisker stimulation. $\boldsymbol{A}$, Schematic of experimental design. $\boldsymbol{B}$, Individual animal mean synapse density (open circles) and group mean (filled circles) shown by layer after $24 \mathrm{~h}$ SRE at P14. C, Example synapses shown by layer for control barrel column. D, Mean percentage change in synapse density after SRE normalized to the P14 mean for each layer. $\boldsymbol{E}$, As in C but for spared barrel column. Scale bar: $C, E, 200 \mathrm{~nm}$.

L1

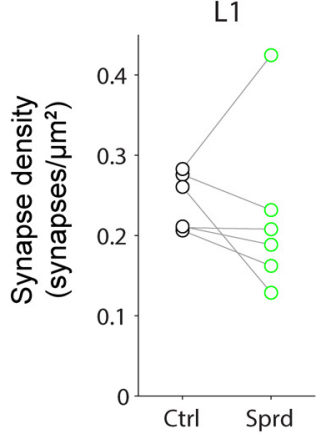

L2

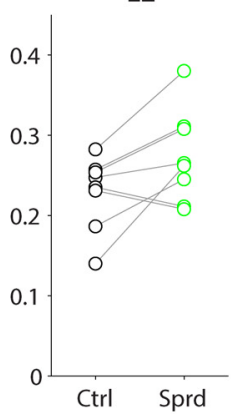

L3

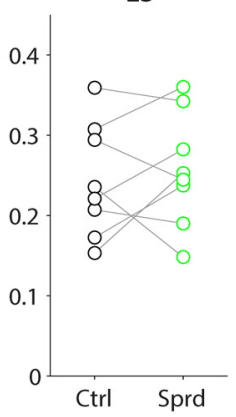

L4

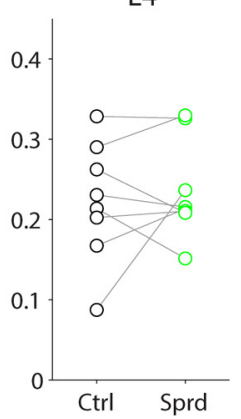

L5A

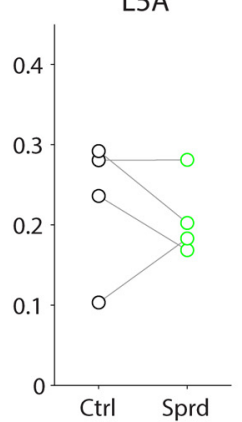

L5B

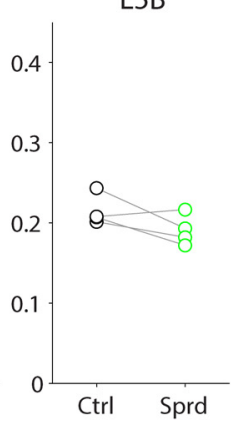

L6

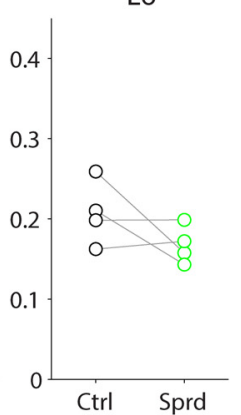

Figure 6. Comparison of synapse density across conditions compared within each animal litter. Mean synapse density for animals grouped by litter and compared for P14 control versus SRE-treated mice. Layer 1- 6 indicated above each plot. Black dots represent control across-animal means for a given litter. Green dots represent the same but after SRE. Gray lines connecting each circle indicate animals were from the same litter. Ctrl, Control; Sprd, spared.

ditions (control, $1.317 \pm 0.667 \mathrm{~Hz}$ vs SRE, $1.363 \pm 0.773 \mathrm{~Hz}$; Fig. $7 C, F)$. There were no changes in either mEPSC and mIPSC amplitude after SRE (mEPSC amplitude, control, $11.166 \pm 3.532 \mathrm{pA}$ vs SRE, $10.111 \pm 4.311 \mathrm{pA}$; mIPSC amplitude, control, $12.482 \pm$ $3.508 \mathrm{pA}$ vs SRE, $10.701 \pm 5.631 \mathrm{pA}$; Fig. $7 D, E, G)$. Because NMDA receptor blockade can influence mini frequency (Larsen et al., 2011; Urban-Ciecko et al., 2014), we did not include NMDA receptor antagonists in our recordings, an approach that might underestimate changes in mEPSC amplitude (Wen and Barth, 2012).

These data indicate that the SRE-dependent changes in synapse density observed by the EPTA synapse detection method could be linked to input changes in L2 pyramidal neurons using electrophysiological recordings. In addition, our experiments in- dicate that the changes observed are likely to stem from alterations in excitatory, not inhibitory, synapses.

\section{Changes in synapse length after $24 \mathrm{~h} \mathrm{SRE}$}

Previous studies have demonstrated that $24 \mathrm{~h}$ of SRE can initiate the strengthening of L4-L3 and L2/3-L3 excitatory synapses, increasing quantal amplitudes by $\sim 25 \%$ over values obtained from control undeprived animals (Clem and Barth, 2006; Wen and Barth, 2011). Thus, we hypothesized that our column-wide analysis of experiencedependent changes in synapse properties would reveal an increase in synapse length, specifically in L3, and potentially other layers that have not been investigated previously.

After SRE in P14 animals, L3 showed a significant, 3\% increase in mean synapse length compared with control unde- 
A
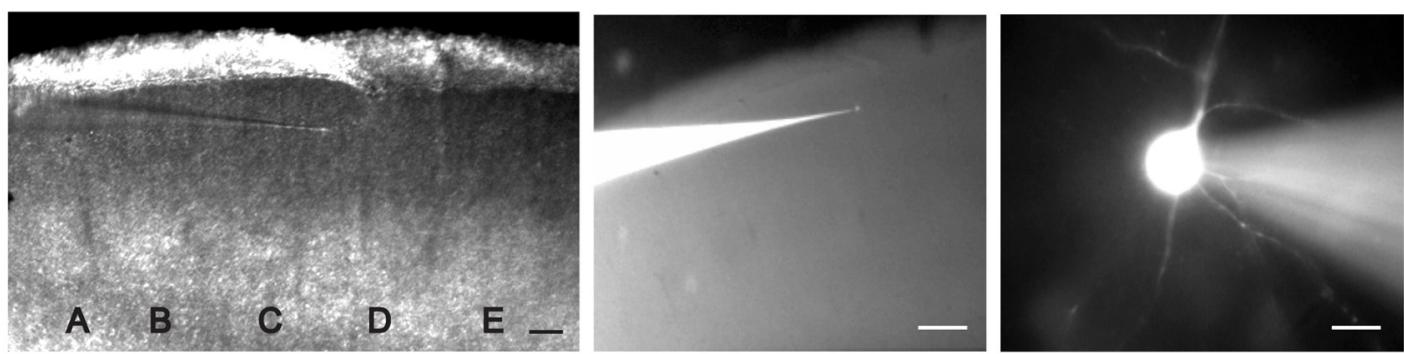

B
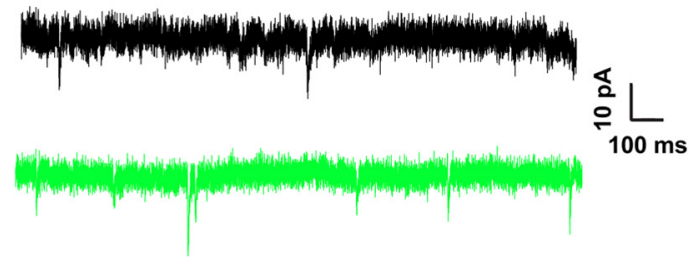

C
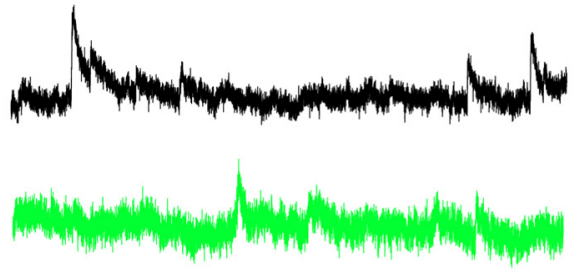

D

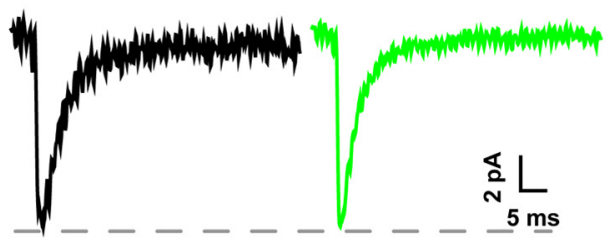

F

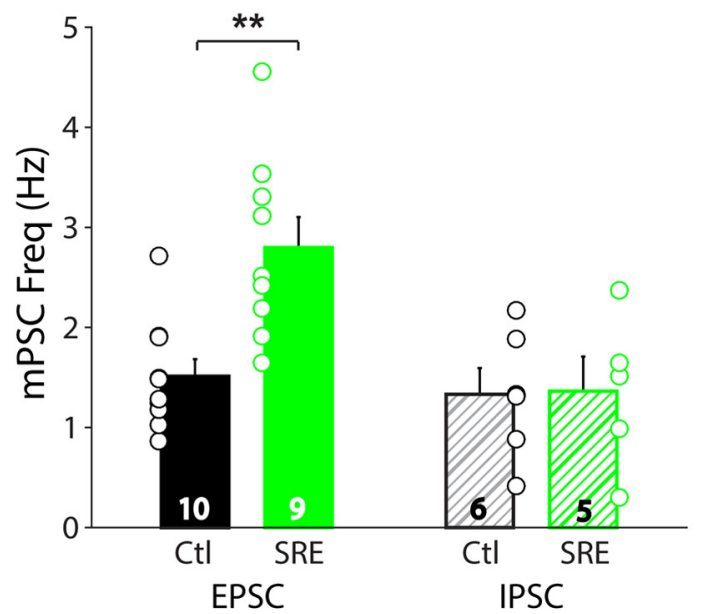

E

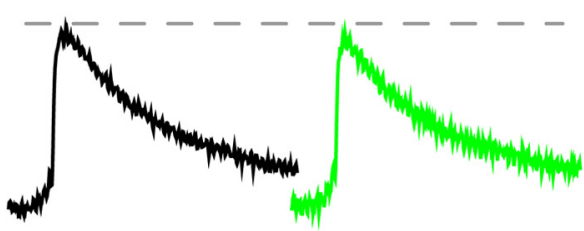

G

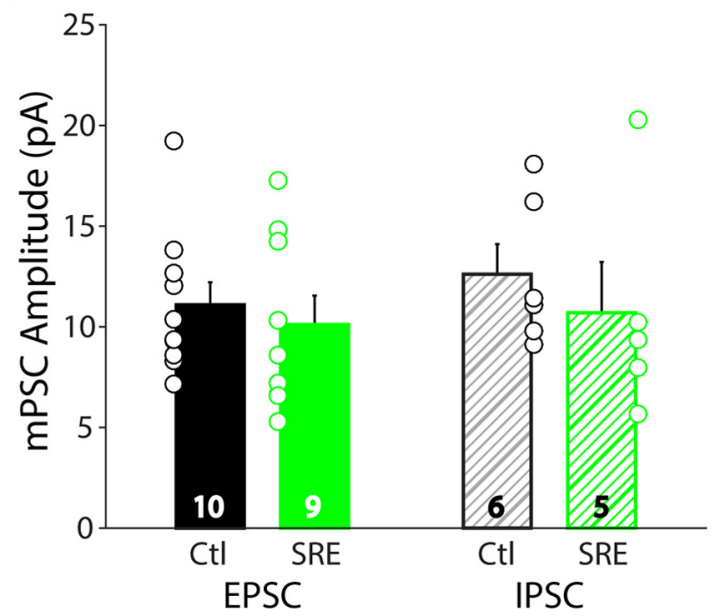

Figure 7. Higher synapse density in L2 correlates with increased mEPSC frequency after SRE. A, Left, Example acute brain slice with all five barrel rows present. Scale bar, $100 \mu \mathrm{m}$. Middle, Low-magnification image showing location of targeted L2 pyramidal neuron. Scale, $200 \mu \mathrm{m}$. Right, L2 pyramidal neuron filled with Alexa Fluor-594. Scale bar, $10 \mu \mathrm{m}$. B, Example traces of mEPSCs in a L2 pyramidal neuron from control (black) and spared (green) barrel column. $\boldsymbol{C}$, As in $\boldsymbol{B}$ but for mIPSCs. $\boldsymbol{D}$, Averaged mEPSCs recorded from L2 pyramidal neurons from control and spared barrel column shows no difference in amplitude. $\boldsymbol{E}$, As in $\boldsymbol{D}$ but for mIPSCs. $\boldsymbol{F}$, Frequency of mEPSCs (solid bars) and mIPSCs (hatched bars) in L2 pyramidal neurons from control (black) and spared (green) barrel columns. Dots indicate values for each recorded cell; numbers in graph bar indicate animals. All averages were calculated across animals. ${ }^{* *}$ indicates two-way ANOVA, $F_{(1,26)}=4.80 ; p=$ 0.038 with Tukey's HSD post hoc correction, $p=0.005$ for mEPSCS. G, As in $\boldsymbol{F}$ but for amplitude mEPSCs and mIPSCs. Two-way ANOVA, $F_{(1,26)}=0.05 ; p=0.820$. Ctl, Control.

prived samples (Fig. 8A; Table 4). L5A analysis suggested that SRE treatment might reduce synapse length, with a $2.5 \%$ reduction in mean length, but this difference was not significant. No other layer exhibited notable changes in length. Because we did not correct for synapse curvature, which disproportionately reduces measured values for the longest synapses, these values may underestimate changes in length.

\section{Discussion}

EPTA-assisted, semiautomated synapse analysis generates a large and rich dataset of candidate synapses across large areas of the brain that can reveal the selective modification of specific neural subcircuits. Here we use this method to quantify changes in synaptic properties across development and alterations of sensory input in mouse somatosensory cortex. Un- 
A

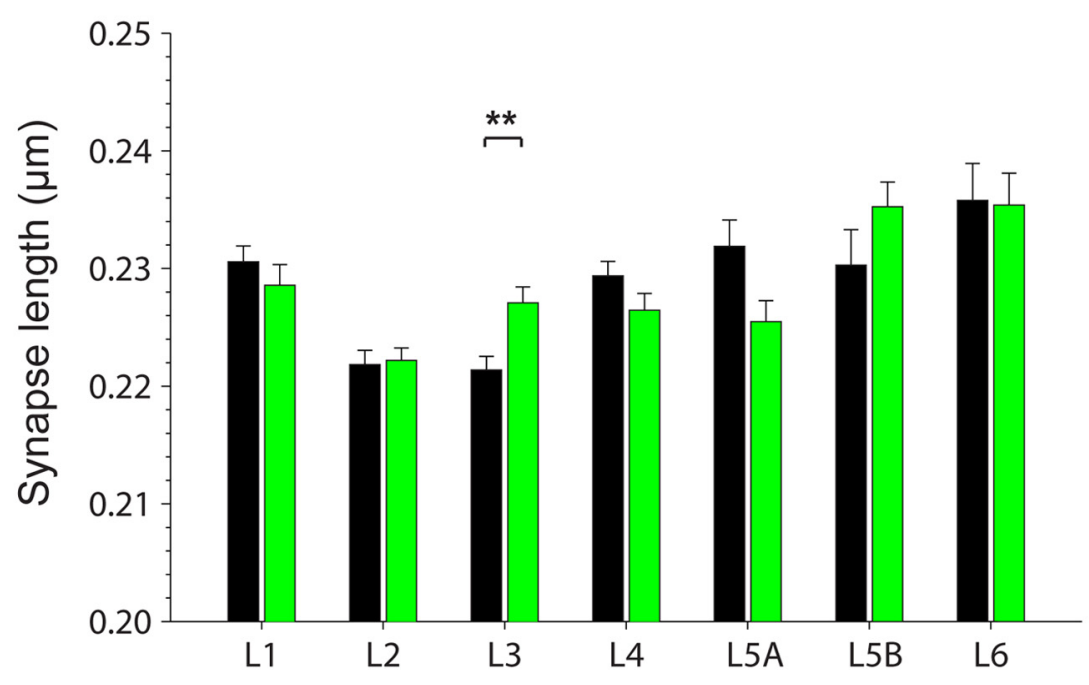

B

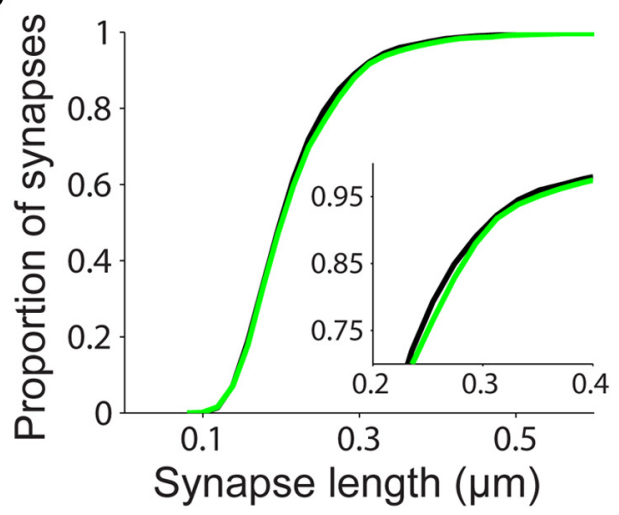

C

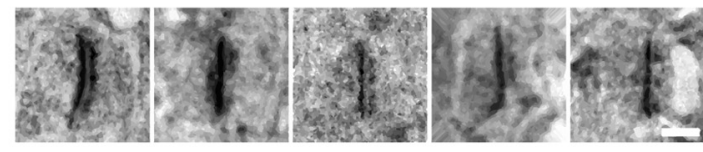

Longest $5 \%$ of synapses - control L3

D

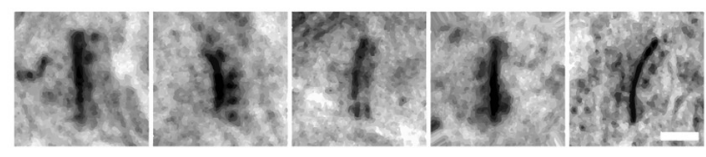

Longest $5 \%$ of synapses - SRE L3

Figure 8. SRE triggers an increase in mean length of $L 3$ synapses. $A$, Average synapse length measured in each cortical layer in control (black) and spared (green) barrel columns. Mean synapse length in L3 is significantly larger after $24 \mathrm{~h}$ SRE. See Table 4 for group $n$. B, Cumulative histogram comparing L3 synapse length in control (black) and spared (green) animals. $p=0.14$ with two-sample K-S test. C, Example images representing longest $5 \%$ of synapses in L3 in control animals. Scale bar, $200 \mathrm{~nm}$. D, As in C but after $24 \mathrm{~h} \mathrm{SRE.}$

Table 4. P14 control versus $24 \mathrm{~h}$ SRE synapse lengths

\begin{tabular}{|c|c|c|c|c|c|c|}
\hline & \multicolumn{3}{|c|}{ P14 control } & \multicolumn{3}{|c|}{ P14 24h SRE } \\
\hline & $\begin{array}{l}\text { Synapses } \\
(n)\end{array}$ & $\begin{array}{l}\text { Animals } \\
(n)^{\dagger}\end{array}$ & $\begin{array}{l}\text { Mean } \pm S D \\
(\mu \mathrm{m})\end{array}$ & $\begin{array}{l}\text { Synapses } \\
(n)\end{array}$ & $\begin{array}{l}\text { Animals } \\
(n)^{\dagger}\end{array}$ & $\begin{array}{l}\text { Mean } \pm S D \\
(\mu \mathrm{m})\end{array}$ \\
\hline L1 & 2917 & 11 & $0.231 \pm 0.072$ & 2362 & 8 & $0.229 \pm 0.085$ \\
\hline L2 & 3336 & 13 & $0.222 \pm 0.069$ & 4574 & 14 & $0.222 \pm 0.071$ \\
\hline L3* & 3647 & 14 & $0.221 \pm 0.070$ & 3171 & 11 & $0.227 \pm 0.077$ \\
\hline L4 & 3595 & 13 & $0.229 \pm 0.073$ & 2669 & 9 & $0.227 \pm 0.074$ \\
\hline L5A & 1448 & 6 & $0.232 \pm 0.083$ & 1459 & 6 & $0.226 \pm 0.068$ \\
\hline L5B & 531 & 2 & $0.230 \pm 0.069$ & 1372 & 7 & $0.235 \pm 0.078$ \\
\hline L6 & 766 & 4 & $0.234 \pm 0.080$ & 842 & 5 & $0.235 \pm 0.079$ \\
\hline
\end{tabular}

*Significant increase after SRE at P14, $p=0.0013$.

${ }^{\dagger}$ Number of animals reflects only those animals in which the algorithm had a precision $\geq 0.75$.

like previous EM studies, in which only a small number of animals and a very restricted anatomical area were characterized, we collected tissue from 48 animals, capturing 24,492 images to detect 39,937 synapses. The dense sampling of synaptic properties across a broad and interconnected cortical circuit revealed both developmental and experience-dependent changes across the cortical column.

First, we found that, at the end of postnatal week 2, animals exhibited a high variability in mean synaptic density that was concentrated in superficial layers, a time period in which these circuits undergo rapid maturation (Maravall et al., 2004; Wen and Barth, 2011). In addition, we discovered that L3 and L5B synapses significantly increase in length between P14 and P18, suggesting the maturation of specific inputs localized to this layer.

SRE, a platform to drive experience-dependent changes in synapse function, was then used to examine at how synapse properties might be changed across the entire cortical column corresponding to the spared sensory input. We found that SRE was associated with an apparent increase in L2 synapse density, an observation corroborated by a highly significant, almost twofold increase mEPSC frequency recorded in L2 pyramidal cells. Synapse length was significantly increased in L3, consistent with previous electrophysiological recordings that show SRE-induced increases in quantal EPSC amplitudes between L4 and L3 pyramidal neurons (Wen and Barth, 2011). We also observed that synapse density in L6 may be reduced after SRE. Overall, these data provide a window into developmental and experiencedependent changes across the cortical column.

Unbiased, high-throughput analysis of experience-dependent synaptic changes

It has been well established that neocortical synapses can be modified by age and experience. EM, array tomography, fluorescence imaging, or electrophysiological experiments have characterized anatomical and functional changes in synapse properties across 
development and experimental conditions (De Felipe et al., 1997; Huttenlocher and Dabholkar, 1997; Lendvai et al., 2000; Trachtenberg et al., 2002; Oray et al., 2004; Holtmaat et al., 2005, 2006; Peters et al., 2008; Hofer et al., 2009; Xu et al., 2009; Yang et al., 2009; Wilbrecht et al., 2010; Chen et al., 2012; Busse and Smith, 2013; Yu et al., 2013; Kuhlman et al., 2014; Wang et al., 2014; Joachimsthaler et al., 2015). These studies show that virtually all layers can be changed during development or by manipulating sensory input, but the sequence of these changes and the specific neural subcircuits involved have not been investigated comprehensively.

This is critical, because in many cases, small differences in experimental conditions or animal age are associated with opposite results. Electrophysiological analyses show that L6 synapses exhibit synaptic strengthening or weakening in response to the same sensory stimulus, based on the developmental state of the circuit (Petrus et al., 2011). Because we observed pronounced variability in synapse density between animal samples-especially in developing animals - our data indicate that large sample sizes may be required to draw strong conclusions about the direction of change. A coherent picture of broad-scale circuit changes will be facilitated by high-throughput methods to evaluate synaptic properties, over multiple animals and conditions.

\section{Correlating anatomical with electrophysiological changes in the spared whisker column}

Anatomical changes in synapse properties were compared with experimental data obtained through electrophysiological analysis. Although analysis of miniature PSCs cannot provide a laminar location for the synapses surveyed by recording from a single neuron, it is used frequently as a screening method to provide a quantitative measure of changes in synaptic function. Other groups have observed a direct correlation between spine density (MacAskill et al., 2014) or excitatory synapse density (Spiegel et al., 2014) with frequency of excitatory synaptic events. Indeed, this method provides a complementary, functional approach to surveying experience-dependent changes in synapse function. The 19\% SRE-dependent increase in synapse density in L2 was associated with a near-doubling of mEPSC frequency in L2 pyramidal neurons. Why the discrepancy? Our EPTA analysis did not enable us to distinguish between excitatory and inhibitory synapses, and a lack of change in inhibitory input (as suggested by mIPSCs measurements) would suppress the aggregate difference in overall synapse density. In addition, L2 dendrites extend into L1 and L3, and unlike EPTA-EM identified synapses, mEPSC measurements likely report these inputs. Functional changes, such as enhanced release probability of synapses, could occur after whisker-evoked plasticity. Finally, the density of other synapse types residing in L2- such as inputs to L5 apical dendrites, inputs from the thalamus, or inhibitory synapses - might be reduced, suppressing the overall magnitude of change.

Mean synapse length in L3 increased after SRE, consistent with previous reports of synaptic potentiation of excitatory synapses in this area (Wen and Barth, 2011). The 25\% increase in quantal EPSC amplitude at L4-L3 synapses observed is much greater than the difference in mean synapse length (3\%) between control and SRE-treated samples in L3. Why might this be the case? Although both L4-L3 and L3-L3 synapses are localized to L3, specifically on the basal dendrites of L3 pyramidal neurons (Feldmeyer et al., 2006; Petreanu et al., 2009), these excitatory synapses constitute only a fraction of the total synapses within L3.
Other major L3 synapses may arise from extracolumnar L3 pyramidal neurons (Bruno et al., 2009), VPM (Petreanu et al., 2009), M1 projection neurons (Petreanu et al., 2009; Kinnischtzke et al., 2014), callosal projections (Petreanu et al., 2007; Molyneaux et al., 2009), local inhibitory neurons (Fino and Yuste, 2011), supragranular inputs to L5 apical dendrites (Petreanu et al., 2009), and other sources. We predict that the small differences in length observed here might reflect large changes in L4-L3 and L3-L3 synapses, without changes or with compensatory reductions in other inputs within this layer.

L6 neurons have been implicated in gain modulation of responses of neurons in the superficial layers (Olsen et al., 2012) by translaminar inhibition and also via corticothalamic projections. EPTA-assisted synapse identification enabled us to identify a pronounced reduction in synaptic density in L6 in the spared whisker barrel column after SRE. Experiencedependent synaptic plasticity in L6 has not been well characterized. Previous studies show that sensory deprivation can trigger reductions in mEPSC amplitude in L6 pyramidal neurons (Petrus et al., 2011), although more targeted studies indicate that thalamocortical inputs in L6 do not undergo experience-dependent changes in early development (Wang et al., 2013; Crocker-Buque et al., 2015).

What synapses might be regulated in L6? L6 neurons primarily receive input from other L6 neurons within and across columns but also receive within-column input from L2/3 (Velez-Fort et al., 2014; DeNardo et al., 2015), L4 (Qi and Feldmeyer, 2015), L5A-L5B (Zarrinpar and Callaway, 2006; Lefort et al., 2009), and the thalamus (Zhang and Deschênes, 1998; Bureau et al., 2006; Oberlaender et al., 2012), and other distant brain areas, such as the motor cortex and secondary somatosensory cortex (Zhang and Deschênes, 1998; Briggs, 2010) and the contralateral hemisphere (Petreanu et al., 2007). These within-column inputs from other layers are relatively rare- only a few percent of L4 neurons, for example, are connected to L6 neurons- but anatomical studies show elaborate axonal arborization of a subset of L6 neurons across different columns (Narayanan et al., 2015), suggesting that these inputs might be a candidate for synaptic rearrangements. Examination of experience-dependent changes in cell-typespecific changes in L6 circuits will be a fruitful area for future investigations.

\section{Limitations of the approach}

Many apparent differences observed in synapse density and length reported here did not reach statistical significance after correction for multiple comparisons, in part because this study attempted to comprehensively investigate column-wide changes in synapse properties, and each new comparison (for example, separately assessing L5A and L5B) made it effectively more difficult to observe statistically significant differences. In addition, the high variance in synapse density observed across animals made it difficult for small differences to achieve statistical significance. This variance, especially pronounced during early development, will impede studies that focus on this time point. Because variability across animals in overall synapse density values decreased as development proceeded, this technique might be more effective at characterizing synaptic changes in more mature circuits. An important limitation of this technique is that it does not distinguish between excitatory and inhibitory synapses or between synapses originating from different sources. Thus, compensatory changes from different input sources, reflecting different synapse types, may mask the overall magnitude of change. 
An important challenge is the development of methods that enable the selective labeling not only of excitatory and inhibitory synapses, but that can differentiate synapses based on presynaptic and postsynaptic identity. Future experiments can address this using genetically encoded molecules recognizable by EM methods that are compatible with high-throughput synapse identification algorithms. Developing a quantitative directory to classify synapse types, across development and experimental conditions, will provide critical information about how circuits change in response to experience and disease and is an important long-term goal.

\section{Potential applications}

Our results show that a high-throughput analysis of synaptic changes can uncover novel loci of synaptic plasticity to guide subsequent targeted experiments, such as electrophysiological recordings to further characterize observed changes. Localization of simultaneous synaptic changes across different neocortical layers or different brain areas may suggest specific subcircuits that are coordinately regulated by different experimental conditions. Because the method is suited for dense, broad-scale anatomical analysis, alterations in synaptic properties across genetic condition, drug exposure, or learning paradigms are feasible.

\section{References}

Bender KJ, Allen CB, Bender VA, Feldman DE (2006) Synaptic basis for whisker deprivation-induced synaptic depression in rat somatosensory cortex. J Neurosci 26:4155-4165. CrossRef Medline

Benedetti BL, Glazewski S, Barth AL (2009) Reliable and precise neuronal firing during sensory plasticity in superficial layers of primary somatosensory cortex. J Neurosci 29:11817-11827. CrossRef Medline

Bloom FE, Aghajanian GK (1966) Cytochemistry of synapses: selective staining for electron microscopy. Science 154:1575-1577. CrossRef Medline

Bloom FE, Aghajanian GK (1968) Fine structural and cytochemical analysis of the staining of synaptic junctions with phosphotungstic acid. J Ultrastruct Res 22:361-375. CrossRef Medline

Briggs F (2010) Organizing principles of cortical layer 6. Front Neural Circuits 4:3. CrossRef Medline

Bruno RM, Hahn TT, Wallace DJ, de Kock CP, Sakmann B (2009) Sensory experience alters specific branches of individual corticocortical axons during development. J Neurosci 29:3172-3181. CrossRef Medline

Bureau I, von Saint Paul F, Svoboda K (2006) Interdigitated paralemniscal and lemniscal pathways in the mouse barrel cortex. PLoS Biol 4:e382. CrossRef Medline

Busse B, Smith S (2013) Automated analysis of a diverse synapse population. PLoS Comput Biol 9:e1002976. CrossRef Medline

Cheetham CE, Hammond MS, Edwards CE, Finnerty GT (2007) Sensory experience alters cortical connectivity and synaptic function site specifically. J Neurosci 27:3456-3465. CrossRef Medline

Cheetham CE, Barnes SJ, Albieri G, Knott GW, Finnerty GT (2014) Pansynaptic enlargement at adult cortical connections strengthened by experience. Cereb Cortex 24:521-531. CrossRef Medline

Chen JL, Villa KL, Cha JW, So PT, Kubota Y, Nedivi E (2012) Clustered dynamics of inhibitory synapses and dendritic spines in the adult neocortex. Neuron 74:361-373. CrossRef Medline

Clem RL, Barth A (2006) Pathway-specific trafficking of native AMPARs by in vivo experience. Neuron 49:663-670. CrossRef Medline

Crocker-Buque A, Brown SM, Kind PC, Isaac JT, Daw MI (2015) Experience-dependent, layer-specific development of divergent thalamocortical connectivity. Cereb Cortex 25:2255-2266. CrossRef Medline

De Felipe J, Marco P, Fairén A, Jones EG (1997) Inhibitory synaptogenesis in mouse somatosensory cortex. Cereb Cortex 7:619-634. CrossRef Medline

DeNardo LA, Berns DS, DeLoach K, Luo L (2015) Connectivity of mouse somatosensory and prefrontal cortex examined with trans-synaptic tracing. Nat Neurosci 18:1687-1697. CrossRef Medline
Diamond ME, Huang W, Ebner FF (1994) Laminar comparison of somatosensory cortical plasticity. Science 265:1885-1888. CrossRef Medline

Feldmeyer D, Lübke J, Sakmann B (2006) Efficacy and connectivity of intracolumnar pairs of layer $2 / 3$ pyramidal cells in the barrel cortex of juvenile rats. J Physiol 575:583-602. CrossRef Medline

Finnerty GT, Roberts LS, Connors BW (1999) Sensory experience modifies the short-term dynamics of neocortical synapses. Nature 400:367-371. CrossRef Medline

Fino E, Yuste R (2011) Dense inhibitory connectivity in neocortex. Neuron 69:1188-1203. CrossRef Medline

Fox K (1992) A critical period for experience-dependent synaptic plasticity in rat barrel cortex. J Neurosci 12:1826-1838. Medline

Frick A, Feldmeyer D, Helmstaedter M, Sakmann B (2008) Monosynaptic connections between pairs of L5A pyramidal neurons in columns of juvenile rat somatosensory cortex. Cereb Cortex 18:397-406. CrossRef Medline

Glazewski S, Fox K (1996) Time course of experience-dependent synaptic potentiation and depression in barrel cortex of adolescent rats. J Neurophysiol 75:1714-1729. Medline

Glazewski S, Benedetti BL, Barth AL (2007) Ipsilateral whiskers suppress experience-dependent plasticity in the barrel cortex. J Neurosci 27:3910 3920. CrossRef Medline

Hildebrandt H, Hoffmann NA, Illing RB (2011) Synaptic reorganization in the adult rat's ventral cochlear nucleus following its total sensory deafferentation. PLoS One 6:e23686. CrossRef Medline

Hofer SB, Mrsic-Flogel TD, Bonhoeffer T, Hübener M (2009) Experience leaves a lasting structural trace in cortical circuits. Nature 457:313-317. CrossRef Medline

Holtmaat A, Svoboda K (2009) Experience-dependent structural synaptic plasticity in the mammalian brain. Nat Rev Neurosci 10:647-658. CrossRef Medline

Holtmaat AJ, Trachtenberg JT, Wilbrecht L, Shepherd GM, Zhang X, Knott GW, Svoboda K (2005) Transient and persistent dendritic spines in the neocortex in vivo. Neuron 45:279-291. CrossRef Medline

Holtmaat A, Wilbrecht L, Knott GW, Welker E, Svoboda K (2006) Experience-dependent and cell-type-specific spine growth in the neocortex. Nature 441:979-983. CrossRef Medline

Huttenlocher PR, Dabholkar AS (1997) Regional differences in synaptogenesis in human cerebral cortex. J Comp Neurol 387:167-178. CrossRef Medline

Jacob V, Petreanu L, Wright N, Svoboda K, Fox K (2012) Regular spiking and intrinsic bursting pyramidal cells show orthogonal forms of experience-dependent plasticity in layer V of barrel cortex. Neuron 73: 391-404. CrossRef Medline

Joachimsthaler B, Brugger D, Skodras A, Schwarz C (2015) Spine loss in primary somatosensory cortex during trace eyeblink conditioning. J Neurosci 35:3772-3781. CrossRef Medline

Jouhanneau JS, Ferrarese L, Estebanez L, Audette NJ, Brecht M, Barth AL, Poulet JF (2014) Cortical fosGFP expression reveals broad receptive field excitatory neurons targeted by POm. Neuron 84:1065-1078. CrossRef Medline

Kharazia VN, Weinberg RJ (1999) Immunogold localization of AMPA and NMDA receptors in somatic sensory cortex of albino rat. J Comp Neurol 412:292-302. CrossRef Medline

Kinnischtzke AK, Simons DJ, Fanselow EE (2014) Motor cortex broadly engages excitatory and inhibitory neurons in somatosensory barrel cortex. Cereb Cortex 24:2237-2248. CrossRef Medline

Kuhlman SJ, O'Connor DH, Fox K, Svoboda K (2014) Structural plasticity within the barrel cortex during initial phases of whisker-dependent learning. J Neurosci 34:6078-6083. CrossRef Medline

Land PW, Simons DJ (1985) Cytochrome oxidase staining in the rat SmI barrel cortex. J Comp Neurol 238:225-235. CrossRef Medline

Larsen RS, Corlew RJ, Henson MA, Roberts AC, Mishina M, Watanabe M, Lipton SA, Nakanishi N, Pérez-Otaño I, Weinberg RJ, Philpot BD (2011) NR3A-containing NMDARs promote neurotransmitter release and spike timing-dependent plasticity. Nat Neurosci 14:338-344. CrossRef Medline

Lefort S, Tomm C, Floyd Sarria JC, Petersen CC (2009) The excitatory neuronal network of the $\mathrm{C} 2$ barrel column in mouse primary somatosensory cortex. Neuron 61:301-316. CrossRef Medline

Lendvai B, Stern EA, Chen B, Svoboda K (2000) Experience-dependent 
plasticity of dendritic spines in the developing rat barrel cortex in vivo. Nature 404:876-881. CrossRef Medline

MacAskill AF, Cassel JM, Carter AG (2014) Cocaine exposure reorganizes cell type- and input-specific connectivity in the nucleus accumbens. Nat Neurosci 17:1198-1207. CrossRef Medline

Maravall M, Stern EA, Svoboda K (2004) Development of intrinsic properties and excitability of layer $2 / 3$ pyramidal neurons during a critical period for sensory maps in rat barrel cortex. J Neurophysiol 92:144-156. CrossRef Medline

Micheva KD, Beaulieu C (1996) Quantitative aspects of synaptogenesis in the rat barrel field cortex with special reference to GABA circuitry. J Comp Neurol 373:340-354. CrossRef Medline

Molyneaux BJ, Arlotta P, Fame RM, MacDonald JL, MacQuarrie KL, Macklis JD (2009) Novel subtype-specific genes identify distinct subpopulations of callosal projection neurons. J Neurosci 29:12343-12354. CrossRef Medline

Narayanan RT, Egger R, Johnson AS, Mansvelder HD, Sakmann B, de Kock CP, Oberlaender M (2015) Beyond columnar organization: cell typeand target layer-specific principles of horizontal axon projection patterns in rat vibrissal cortex. Cereb Cortex 25:4450-4468. CrossRef Medline

Navlakha S, Suhan J, Barth AL, Bar-Joseph Z (2013) A high-throughput framework to detect synapses in electron microscopy images. Bioinformatics 29:i9-i17. CrossRef Medline

Oberlaender M, Boudewijns ZS, Kleele T, Mansvelder HD, Sakmann B, de Kock CP (2011) Three-dimensional axon morphologies of individual layer 5 neurons indicate cell type-specific intracortical pathways for whisker motion and touch. Proc Natl Acad Sci U S A 108:4188-4193. CrossRef Medline

Oberlaender M, de Kock CP, Bruno RM, Ramirez A, Meyer HS, Dercksen VJ, Helmstaedter M, Sakmann B (2012) Cell type-specific threedimensional structure of thalamocortical circuits in a column of rat vibrissal cortex. Cereb Cortex 22:2375-2391. CrossRef Medline

Olsen SR, Bortone DS, Adesnik H, Scanziani M (2012) Gain control by layer six in cortical circuits of vision. Nature 483:47-52. CrossRef Medline

Oray S, Majewska A, Sur M (2004) Dendritic spine dynamics are regulated by monocular deprivation and extracellular matrix degradation. Neuron 44:1021-1030. CrossRef Medline

Peters A, Sethares C, Luebke JI (2008) Synapses are lost during aging in the primate prefrontal cortex. Neuroscience 152:970-981. CrossRef Medline

Petreanu L, Huber D, Sobczyk A, Svoboda K (2007) Channelrhodopsin-2assisted circuit mapping of long-range callosal projections. Nat Neurosci 10:663-668. CrossRef Medline

Petreanu L, Mao T, Sternson SM, Svoboda K (2009) The subcellular organization of neocortical excitatory connections. Nature 457:1142-1145. CrossRef Medline

Petrus E, Anguh TT, Pho H, Lee A, Gammon N, Lee HK (2011) Developmental switch in the polarity of experience-dependent synaptic changes in layer 6 of mouse visual cortex. J Neurophysiol 106:2499-2505. CrossRef Medline

Qi G, Feldmeyer D (2015) Dendritic target region-specific formation of synapses between excitatory layer 4 neurons and layer 6 pyramidal cells. Cereb Cortex. Advance online publication. Retrieved November 16, 2015. doi:10.1093/cercor/bhu334. CrossRef Medline

Reynolds ES (1963) The use of lead citrate at high pH as an electron-opaque stain in electron microscopy. J Cell Biol 17:208-212. CrossRef Medline

Seelke AM, Perkeybile AM, Grunewald R, Bales KL, Krubitzer LA (2015) Individual differences in cortical connections of somatosensory cortex are associated with parental rearing style in prairie voles (Microtus ochrogaster). J Comp Neurol. Advance online publication. Retrieved November 16, 2015. doi:10.1002/cne.23837. CrossRef Medline

Silberberg G, Markram H (2007) Disynaptic inhibition between neocortical pyramidal cells mediated by Martinotti cells. Neuron 53:735-746. CrossRef Medline

Spiegel I, Mardinly AR, Gabel HW, Bazinet JE, Couch CH, Tzeng CP, Harmin DA, Greenberg ME (2014) Npas4 regulates excitatory-inhibitory balance within neural circuits through cell-type-specific gene programs. Cell 157:1216-1229. CrossRef Medline

Trachtenberg JT, Chen BE, Knott GW, Feng G, Sanes JR, Welker E, Svoboda $\mathrm{K}$ (2002) Long-term in vivo imaging of experience-dependent synaptic plasticity in adult cortex. Nature 420:788-794. CrossRef Medline

Urban-Ciecko J, Wen JA, Parekh PK, Barth AL (2014) Experiencedependent regulation of presynaptic NMDARs enhances neurotransmitter release at neocortical synapses. Learn Mem 22:47-55. CrossRef Medline

Vélez-Fort M, Rousseau CV, Niedworok CJ, Wickersham IR, Rancz EA, Brown AP, Strom M, Margrie TW (2014) The stimulus selectivity and connectivity of layer six principal cells reveals cortical microcircuits underlying visual processing. Neuron 83:1431-1443. CrossRef Medline

Wang GX, Smith SJ, Mourrain P (2014) Fmr1 KO and fenobam treatment differentially impact distinct synapse populations of mouse neocortex. Neuron 84:1273-1286. CrossRef Medline

Wang L, Kloc M, Gu Y, Ge S, Maffei A (2013) Layer-specific experiencedependent rewiring of thalamocortical circuits. J Neurosci 33:4181-4191. CrossRef Medline

Wen JA, Barth AL (2011) Input-specific critical periods for experiencedependent plasticity in layer 2/3 pyramidal neurons. J Neurosci 31:44564465. CrossRef Medline

Wen JA, Barth AL (2012) Synaptic lability after experience-dependent plasticity is not mediated by calcium-permeable AMPARs. Front Mol Neurosci 5:15. CrossRef Medline

Wen JA, DeBlois MC, Barth AL (2013) Initiation, labile, and stabilization phases of experience-dependent plasticity at neocortical synapses. J Neurosci 33:8483-8493. CrossRef Medline

White EL, Weinfeld L, Lev DL (1997) A survey of morphogenesis during the early postnatal period in PMBSF barrels of mouse SmI cortex with emphasis on barrel D4. Somatos Mot Res 14:34-55. CrossRef Medline

Wilbrecht L, Holtmaat A, Wright N, Fox K, Svoboda K (2010) Structural plasticity underlies experience-dependent functional plasticity of cortical circuits. J Neurosci 30:4927-4932. CrossRef Medline

Wimmer VC, Bruno RM, de Kock CP, Kuner T, Sakmann B (2010) Dimensions of a projection column and architecture of VPM and POm axons in rat vibrissal cortex. Cereb Cortex 20:2265-2276. CrossRef Medline

Xu T, Yu X, Perlik AJ, Tobin WF, Zweig JA, Tennant K, Jones T, Zuo Y (2009) Rapid formation and selective stabilization of synapses for enduring motor memories. Nature 462:915-919. CrossRef Medline

Yang G, Pan F, Gan WB (2009) Stably maintained dendritic spines are associated with lifelong memories. Nature 462:920-924. CrossRef Medline

Yu X, Wang G, Gilmore A, Yee AX, Li X, Xu T, Smith SJ, Chen L, Zuo Y (2013) Accelerated experience-dependent pruning of cortical synapses in ephrin-A2 knockout mice. Neuron 80:64-71. CrossRef Medline

Zarrinpar A, Callaway EM (2006) Local connections to specific types of layer 6 neurons in the rat visual cortex. J Neurophysiol 95:1751-1761. CrossRef Medline

Zhang ZW, Deschênes M (1998) Projections to layer VI of the posteromedial barrel field in the rat: a reappraisal of the role of corticothalamic pathways. Cereb Cortex 8:428-436. CrossRef Medline

Zuiderveld K (1994) Contrast limited adaptive histogram equalization. In: Graphics gems IV, pp 474-485. Cambridge, MA: Academic.

Zuo Y, Yang G, Kwon E, Gan WB (2005) Long-term sensory deprivation prevents dendritic spine loss in primary somatosensory cortex. Nature 436:261-265. CrossRef Medline 